\title{
From Gene Targeting to Genome Editing: Transgenic animals applications and beyond
}

\author{
MAURÍCIO ROCHA-MARTINS ${ }^{1,2}$, GABRIEL R. CAVALHEIRO ${ }^{1,2}$, GABRIEL \\ E. MATOS-RODRIGUES ${ }^{1,3}$ and RODRIGO A.P. MARTINS ${ }^{1}$

\begin{abstract}
${ }^{1}$ Programa de Biologia Celular e do Desenvolvimento, Instituto de Ciências Biomédicas/ICB, Universidade Federal do Rio de Janeiro/UFRJ, Avenida Carlos Chagas Filho, 373, Centro de Ciências da Saúde/CCS, Bloco F, Sala F1-08, Cidade Universitária, 21941-902 Rio de Janeiro, RJ, Brasil ${ }^{2}$ Programa de Pós Graduação em Ciências Biológicas (Biofísica), Instituto de Biofísica Carlos Chagas Filho/IBCCF, Universidade Federal do Rio de Janeiro, Avenida Carlos Chagas Filho, 373, Bloco G, $1^{\circ}$ andar, sala 19, Cidade Universitária, 21941-902 Rio de Janeiro, RJ, Brasil Janeiro, Avenida Carlos Chagas, 373, Bloco K, $2^{\circ}$ andar, sala 27, Cidade Universitária, 21941-902 Rio de Janeiro, RJ, Brasil
\end{abstract} \\ ${ }^{3}$ Programa de Pós Graduação em Ciências Morfológicas, Instituto de Ciências Biomédicas/ICB, Universidade Federal do Rio de \\ Manuscript received on December 21, 2014; accepted for publication on February 26, 2015
}

\begin{abstract}
Genome modification technologies are powerful tools for molecular biology and related areas. Advances in animal transgenesis and genome editing technologies during the past three decades allowed systematic interrogation of gene function that can help model how the genome influences cellular physiology. Genetic engineering via homologous recombination (HR) has been the standard method to modify genomic sequences. Nevertheless, nuclease-guided genome editing methods that were developed recently, such as ZFN, TALEN and CRISPR/Cas, opened new perspectives for biomedical research. Here, we present a brief historical perspective of genome modification methods, focusing on transgenic mice models. Moreover, we describe how new techniques were discovered and improved, present the paradigm shifts and discuss their limitations and applications for biomedical research as well as possible future directions.
\end{abstract}

Key words: Homologous recombination, DNA repair, Cre-LoxP, ZFN, TALEN, CRISPR/Cas9.

\section{INTRODUCTION}

A universal question in biology is how the genome translates into phenotypes giving rise to the endless forms of nature. It dates back to the first evidences that genes encode individual proteins and the seminal discovery of DNA's three-dimensional structure (Beadle and Tatum 1941, Watson and Crick 1953). Since then, molecular biology has

Correspondence to: Rodrigo Alves Portela Martins

E-mail: rodrigo.martins@icb.ufrj.br developed at a rapid pace guided by the Central Dogma (Crick 1958) and somehow impregnated by genetic determinism. Over the second half of the $20^{\text {th }}$ century, advances in the generation of transgenic organisms made its way from prokaryotic to vertebrate model organisms, including mice.

Integration of a foreign DNA sequences into host genomes characterized the first attempts to study gene function in vivo (Brinster et al. 1981, 1982, Spradling and Rubin 1982). In mice, pioneering studies generated non-targeted 
genetic modifications in somatic cells through microinjection of exogenous DNA into fertilized eggs (Brinster et al. 1981, 1982, Palmiter et al. 1982). Shortly after, a series of groundbreaking studies described the disruption of endogenous gene expression through targeted modifications that were transmitted through germ line cells (reviewed in (Capecchi 2005)). The discoveries that allowed targeted genetic inactivation in the mouse genome, through the use of embryonic stem cells, granted the Nobel Prize award in Physiology and Medicine 2007 to Drs. Mario Capecchi, Martin Evans and Oliver Smithies.

The establishment of this technique led to a revolution in the ability to interrogate the relevance of specific genes revealing the molecular basis of numerous biological phenomena from animal diversity to human diseases. Advances in DNA sequencing technologies allowed the study of eukaryote's genomes at unprecedented resolution and taught us that the variations found in the coding regions were too small to account for the substantial organismal differences (King and Wilson 1975, Whitehead and Sackstein 1985, McGinnis and Krumlauf 1992, Adams et al. 2000, Venter et al. 2001). The lack of correlation between genome size or the number of protein-coding genes with organism complexity was puzzling. Additional findings supported the notion that organismal complexity arose from more elaborate regulatory networks rather than the appearance of new genes (Levine and Tjian 2003). This scenario exacerbated the need to go beyond sequence comparisons and made clear the need to study gene function in various contexts (e.g. cells, tissues, developmental stages and organisms) to elucidate the relationship between an organism's genome and its phenotype. Studies on gene targeting and genome edition developed over the last thirty years advanced transgenesis in an unimaginable scale. Nowadays, we have learned to manipulate the genome in more efficient (e.g. less time consuming) and refined ways (e.g. spatial and timing), to generate transgenics in non-model organisms and to edit the genome at a systems level (e.g. target multiple genetic pathways simultaneously).

Here, we review and discuss the various methods to create targeted modifications in the genome and present a historical perspective of the generation of transgenic mice models that benefited from these advances. We describe recent technologies that greatly improved transgenesis, such as ZFNs, TALENs and CRISPR/Cas, its biological applications from basic research to biotechnology, while highlighting challenges as well as future perspectives.

\section{GENE TARGETING BY HOMOLOGOUS RECOMBINATION}

In the early 80 's, a series of pioneer studies generated transgenic mice by microinjecting fertilized egg cells even before the establishment of homology based methods (Gordon et al. 1980, Brinster et al. 1981, 1982, 1984, Palmiter et al. 1982). These studies performed the implantation of eggs previously injected with plasmids encoding viral antigens into pseudo pregnant recipient females. The insertion of various copies of the transgene in the genome, its expression in different somatic cell types and the transmission through germ line cells was observed. However, integration occurred in a non-targeted manner and without copy number control (Brinster et al. 1981). Using similar methodologies of zygote microinjection, transgenic rabbits, pigs and sheep were also produced (Hammer et al. 1985). These studies represented a major advance in the areas of animal science and transgenic animal generation. Later, it became clear that these genetic modifications could disturb gene expression patterns, induce mutations and/or gene inactivation in the host genome.

The introduction of transgenes in the genome in a targeted manner was only possible with a better understanding of DNA repair by homologous recombination (HR) (Folger et al. 1982, 1984, Smithies et al. 1985). Using this knowledge the groups led by Mario Capecchi and Raju Kucherlapati generated targeted genetic modifications in 
cultured mammalian cells (reviewed in Capecchi 1989, 2005). By electroporation or microinjection, exogenous DNA constructs could be introduced as a template of the target genomic sequence. These targeting vectors should have high homology with the targeted genomic sequence to be recognized by the HR machinery in order to introduce different types of modifications, including insertion or deletion. However, the targeting event occurred in a small percentage of the transfected mammalian cells making it unfeasible to efficiently target a fertilized egg and generate a whole transgenic animal (Capecchi 1989, Capecchi 2005).

Establishment of embryonic stem (ES) cells culture (Martin 1981) allowed the use of HRdependent modifications described above to target specific loci of mouse pluripotent cells. Few successful strategies previously used in other mammalian cell types were employed to select the ES clones that underwent HR. Targeted ES cells carrying exogenous DNA sequences (antibiotic resistance genes - ARG), such as neomycinresistance gene $\left(n e o^{\prime}\right)$, could be selected (positive selection). However, positive and negative strategies of selection became necessary, since the integration of a targeting vector and the $n e o^{r}$ at random sites through non-homologous recombination also occurred. The use of a vector combining the herpes virus thymidine kinase gene (HSV-tk), outside of the region to be recombined, with the neor ${ }^{r}$ allowed the selection of ES cells that contained the desired targeting. Integration through non-homologous recombination generated ES cells expressing the HSV-tk enzyme that were sensitive to FIAU (negative selection) (Mansour et al. 1988). In 1987, the groups of Drs. Capecchi and Smithies reported the targeting of the HPRT gene in mouse ES cells. As written by Dr. Capecchi, the protocol described in these papers "should be useful for targeting mutations into any gene" (Doetschman et al. 1987, Thomas and Capecchi 1987). Following the established methodology of ES cells targeted modification, several groups developed knockout mice for various genes.
In order to target desired genes in vivo, transgenic clones of ES cells were injected in the inner mass of blastocysts that were subsequently implanted into pseudo pregnant females which gave birth to chimeric animals. Mice with different coat patterns were used to screen the offspring chimeras containing cells derived from the transfected ES cells. The chimeric animals containing genetically modified germ line cells transmitted the transgenes to their offspring. Then, heterozygous mice crossing led to the generation of homozygous transgenic mice. Approaches to inactivate an endogenous gene included the replacement of the targeted region or the insertion of a neo ${ }^{r}$ within the coding region to disrupt the open reading frame (ORF) and gene expression. Altogether, the advances described above culminated in the generation of the first gene knockout mice (Joyner et al. 1989, Koller et al. 1989, 1990, Schwartzberg et al. 1989, Zijlstra et al. 1989, Thomas and Capecchi 1990). These pioneering methodologies also allowed the development of knockins with or without cell specific promoters, which could drive transgene expression in a restricted subset of cells or in the whole animal (Okabe et al. 1997, Tamamaki et al. 2003, Yang et al. 2004, Ma et al. 2014).

Transgenic mice generated through HR standard methods already enabled control of gene expression timing and reversibility by the use of drug-inducible transgenes. Two types of engineered tetracyclin receptors that work as drug-modulated transcription factors have been developed: the rTA is transcriptionally active after doxycycline treatment, while the rtTA receptor is prevented from binding DNA. To achieve drugcontrolled transgene up- or down-regulation, two different lines are required: one with the expression of the receptor (rTA or rtTA) and the other with a transgene under the control of a promoter region responsive to the tetracyclin receptor. In mice containing both transgenes, gene expression is regulated by the tetracyclin treatment (Furth et al. 1994, Lewandoski 2001, Sun et al. 2007). 
Relevant findings in various areas of biomedical research (e.g. cancer, immunology, developmental biology) were achieved using knockout and knockin mice, including the use oftransgenic mice to model human diseases (He et al. 1997). Importantly, as emphasized in the following section, transgenic mouse models generated by the use of HR standard methods have limitations, in particular embryo lethality, phenotypes caused by non-autonomous gene function and limited or complicated tools to generate gene knockout mice with temporal and cell type/tissue specificity. As described below, new biological tools were developed to bypass these issues.

RECOMBINASE-BASED CONDITIONAL TRANSGENICS: CRE-LOXP AND FLP-FRT SYSTEMS

In vivo germ line gene targeting can lead to premature death, making it impossible to evaluate phenotypes afterwards. In mice, about $30-40 \%$ of the germ line knockouts are embryonic or perinatal lethal (Adams et al. 2013). Moreover, some of the phenotypes of multiple organ malformation may be the consequence of non-autonomous effects, since the development of some tissues may depend on the correct development of others, complicating the task of fully understanding gene function (Clarke et al. 1992, Wu et al. 2003). Altogether, these negative features of transgenic organisms that carried genetic modification in all somatic cells increased the desire for alternative transgenic models with a tissue- or developmental stage- specific inactivation of the genes of interest.

Site-specific recombinases (SSR) have been used to modify the genome with temporal and cell type specificity. Different types of recombinases have been described, but here we will focus on the two SSR systems most widely used in transgenic models: the Cre-LoxP and Flp-FRT, members of the integrase family of recombinases (Turan and Bode 2011). The Cre-LoxP system was first characterized in the bacteriophage P1 and is responsible for genomic recombination during bacterial division. The Cre (cyclization recombination) recombinase is a $38 \mathrm{kDa}$ protein that can catalyze the recombination of two specific LoxP sequences (locus of crossing-over of P1) (Sauer and Henderson 1988). The Flp recombinase, characterized in $S$. cerevisiae, recognizes the FRT sites (Flp recombinase recognition target) (Gates and Cox 1988, Branda and Dymecki 2004). Although not identical, the sites recognized by Cre and Flp display high similarities. These sequences are formed by $34 \mathrm{bp}$ consensus sequence with two 13 bp palindromic sequences separated by an 8 bp spacer region that is responsible for the sequences orientation (Sternberg and Hamilton 1981, McLeod et al. 1986). To enable recombination, two SSR enzymes monomers bind to each recognition site and mediate a Holliday junction between them before completing recombination. Both systems exhibit high specificity and do not need cofactors. The orientation of the recognition site determines the genetic modification catalyzed by SSR enzymes. When the sites have the same orientation the recombinase excise the sequence in between them irreversibly, while, in the case of opposite orientation, the enzyme drives the inversion of the flanked region (Grindley et al. 2006, Turan and Bode 2011).

Excision of genomic regions by SSR enzymes was a valuable tool to develop transgenic models that bypassed some of the limitations of the first generation of knockouts. To achieve genetic inactivation in cell type-specific manner, it is necessary that the recombinase is expressed in the cells containing specific exons or entire genes flanked by FRT or LoxP sequences. To do so, two independent transgenic mice are crossed: one carrying the recognition sites flanking the region to be excised and the other displaying the coding sequence of the SSR enzyme under the control of cell-type-specific promoters. Pups carrying both transgenes will have knockout (Cre- or Flpexpressing) and non-recombined (Cre- or Flpnegative) cells (Fig. 1A) (Sauer and Henderson 1988, Golic and Lindquist 1989). In addition to the excision of coding regions, SRR-mediated excision 


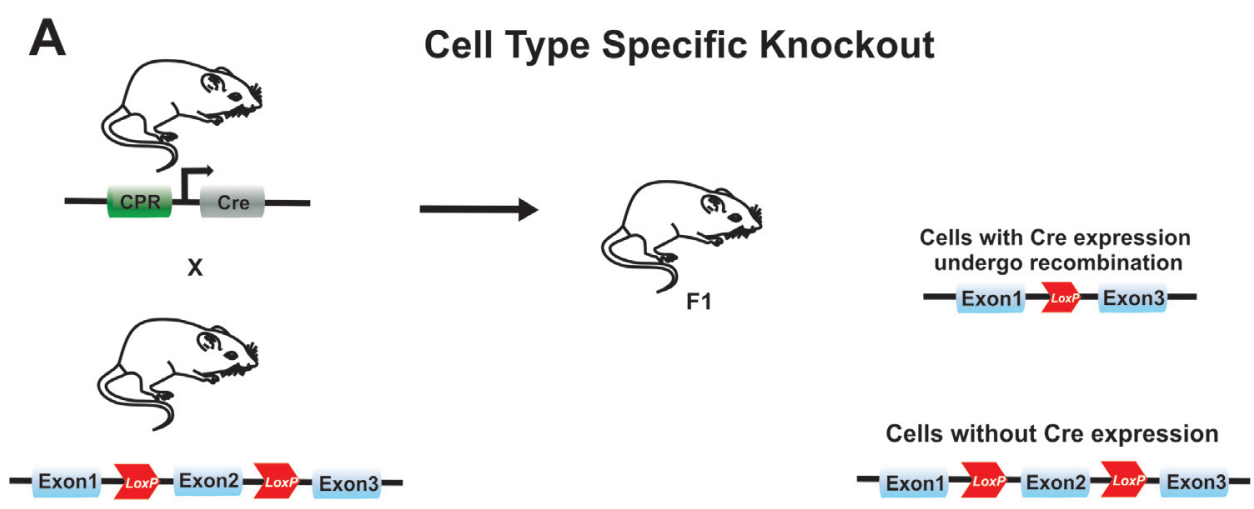

B

Temporal Cell Type Specific Knockout
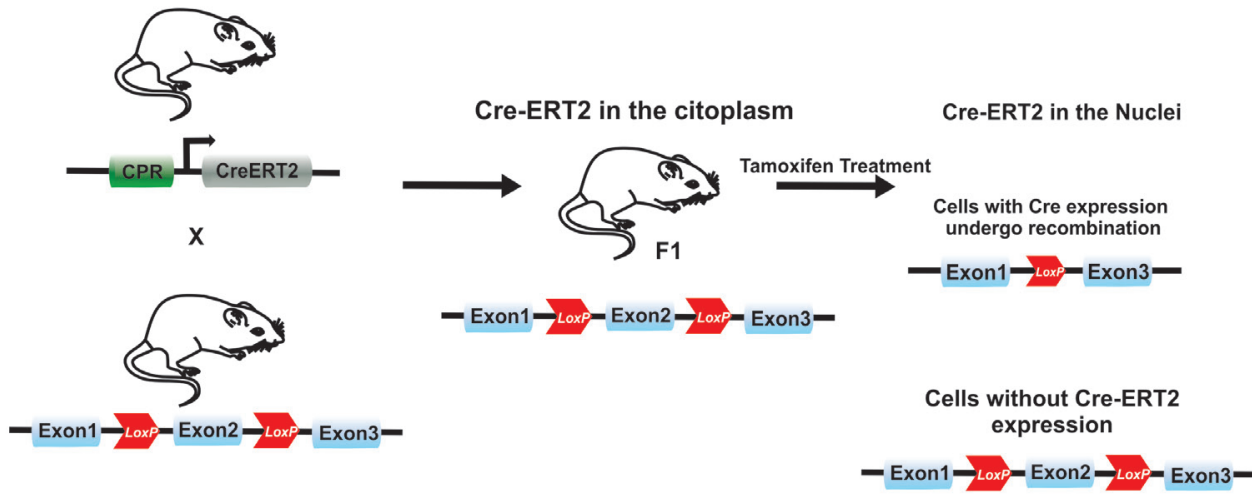

C

Knock-in Recombination Reporter

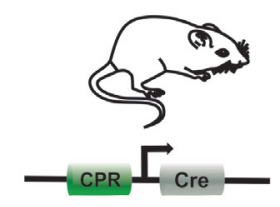

$\mathbf{x}$

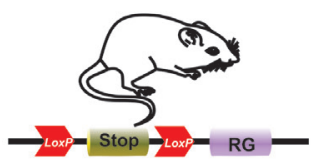

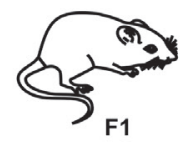

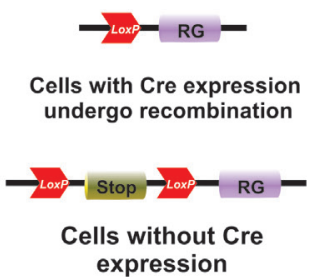

Figure 1 - In vivo transgenesis by SSR-systems: (A) Conditional knockout (cKO) mice may be generated by mating two different lines of transgenic mice: One carrying a SSR enzyme (e.g. Cre) under the control of a cell type-specific promoter (CPR) and the other containing coding regions of the gene of interest flanked by LoxP sequences. Offspring of this mating carrying both transgenes will undergo genetic inactivation only in cells expressing Cre that will recombine the LoxP flanked region. In cells without Cre expression no recombination or gene inactivation will occur. (B) Temporal control of Cre-mediate recombination may be achieved by the use of a chimeric Cre protein (Cre-ERT2). The Cre-ERT2 only translocates to the nucleus and catalyze the recombination after tamoxifen treatment. (C) Knockin recombination reporter mice usually carry a construct with a stop codon flanked by $L o x P$ sequences followed by a reporter gene (RG). In mice carrying this transgene, RG is turned on only in cells expressing Cre, where the stop codon was excised. In the Cre negative cells, the RG is not expressed. These reporter lines allow researchers to track cells/ tissues that underwent Cre-mediated recombination and to perform lineage tracing experiments. 
was also used to generate chimeric proteins (e.g.: constitutively active beta-catenin) (Harada et al. 1999) and to remove entire chromosomes (Lewandoski and Martin 1997). The use of specific promoter regions to drive Cre or Flp expression allowed researchers to modify the genome in specific cells/tissues and/or specific developmental stages. Therefore, application of SSR enzymes represented a breakthrough for in vivo genetic modifications (Branda and Dymecki 2004).

These approaches were used in mice to switch on transgenes in a tissue-specific manner (Lakso et al. 1992, Orban et al. 1992). By the time the first SSR-dependent knockin mice was generated, it was already known that SV40 T overexpression triggered tumorigenesis in the lens (Mahon et al. 1987). Researchers aimed to establish a proof-ofprinciple that Cre expression could be restricted to a specific tissue and drive recombination of LoxP sites in vivo. A mouse line carrying a transgene containing the SV40 $\mathrm{T}$ antigen coding sequence downstream of a $\operatorname{LoxP}$-flanked stop codon was mated with another harboring Cre under the control of the lens-specific $\alpha \mathrm{A}$-crystallin promoter. The offspring of these mice expressed SV40 T only in the lens and developed lens tumors, showing that SSR systems could function in vivo (Lakso et al. 1992).

SSR enzymes were also used to improve the procedures of transgenic mice generation. As explained, antibiotic resistance genes (ARG) are required for selection of ES-containing engineered transgenes. However, it was demonstrated that, in some cases, ARG constructs could disrupt gene expression nearby the transgene locus (Scacheri et al. 2001). To solve this problem, recognition sites of Cre or Flp surrounding the ARG region were inserted in the transgene. When mice containing this transgene were crossed with others expressing the correspondent SSR enzyme ubiquitously, the ARG region was excised from the genome of the offspring (Ren et al. 2002, Tamamaki et al. 2003, Favaro et al. 2009, Ma et al. 2014).
Mouse lines containing modified versions of the Cre allowed a more refined control of the timing of recombinase-mediated excision (Tronche et al. 2002, Branda and Dymecki 2004, Lao et al. 2012). The Cre-ERT2 is a chimeric protein that only translocates to the nucleus in the presence of tamoxifen. Therefore, regardless of ubiquitous or cell type-specific expression of Cre-ERT2, the Cre-mediated recombination will only occur after tamoxifen treatment, providing sophisticated timing control capabilities (Figure 1B) (Ahn and Joyner 2004, Lagace et al. 2007). Recently, a CreERT2 under the control of the Axin promoter (AxinCre-ERT2) was used in an elegant lineage tracing experiment to label $\mathrm{Wnt} / \beta$-catenin responsive cells at different developmental time points. In addition to previously described recombinase-based lineage tracing experiments (Jensen and Dymecki 2014), these studies showed that Cre recombinase is suitable to leave a permanent genetic mark in the recombined cells that responded to a given ligand/ morphogen/hormone. Interestingly, the daughters of the recombined cell will also express the reporter gene (van Amerongen et al. 2012, Bowman et al. 2013).

An extremely important requirement when using the transgenic lines that express SSR enzymes is to characterize the pattern of expression and activity of the recombinases in order to define where and when genetic inactivation will occur. Multiple approaches have been used, such as immunostaining for SSR enzymes and mouse lines in which the expression of a reporter gene is dependent on the SSR activity (Buchholz et al. 1996, Schwenk et al. 1997, Lobe et al. 1999, Yamamoto et al. 2009). In the latter, the transgene must contain a ubiquitous promoter and LoxP (or FRT) recognition sites flanking a stop codon (LoxP-Stop-LoxP - LSL) upstream of a reporter gene (e.g. GFP, RFP, $\beta$-galactosidase or alkaline phosphatase). In mice carrying this transgene, only cells with Cre activity will recombine the stop codon and express the reporter gene (Fig. 1C). That way it became possible to characterize where and/or 
when the recombination and, most likely, the Cremediated genetic inactivation event occurred. As mentioned, these LSL cassettes were also used for Cre-dependent overexpression. In this case, usually the LSL is located in between the coding sequence of the gene and its transcription initiation site so the removal of the stop codon allows overexpression of the gene.

Even though the generation of transgenic animals using SSR based transgenesis represented a major advance in the field, there are several limitations. First, at least two different transgenic lines (Cre and LoxP lines) are required to achieve tissue and/or developmental stage-specific knockout or knockin mice. When double or triple knockout are intended or when a reporter of Cre recombination is needed in the same animal, the number of transgenes and the amount of crossings necessary can be extremely laborious and time consuming. Second, these SSR-mediated genetic modifications are not feasible to modify single or few nucleotides (e.g. point mutations). Importantly, the use of recombinase-based methods requires careful analysis of the biological effects of the SSR enzymes. In some Cre lines, the expression of Cre alone, regardless of genetic inactivation, was sufficient to induce some phenotype, such as cell death, chromosomal aberrations, DNA damage and sterility (Schmidt et al. 2000, Loonstra et al. 2001, Forni et al. 2006, Schmidt-Supprian et al. 2007). Another important issue in some Cre mouse lines is the allele parental inheritance. There are reports of different Cre expression and/or activity patterns depending on parental inheritance (Hayashi et al. 2003, MacPherson et al. 2004). Cre-mediated recombination of LoxP sequences may also vary depending on the position of the LoxP sequence in the genome (Vooijs et al. 2001). Some of these limitations were solved by the methods of genome edition to be described next.

\section{GENOME EDITION BY NUCLEASES}

In the last decade, new methodologies of genome manipulation have emerged. A series of custom target nucleases with the ability to specifically target the genomic region of interest and cleave the phosphodiester bonds have been developed (Urnov et al. 2005, Miller et al. 2007, Christian et al. 2010, Miller et al. 2010, Kim and Kim 2014). The broad concept underlying the new genome editing tools is that by stimulating DNA double-strand breaks (DSBs) at a target region, the endogenous repair machinery of the cell could be hijacked to introduce targeted mutations. In the absence of a homologous repair template, InDels (insertions/deletions) may occur via error-prone non-homologous end joining (NHEJ). These may alter the open reading frame (ORF) of the target gene leading to a premature stop codon or translation of a scrambled amino acid sequence. Notably, the InDels induced by NHEJ are random, therefore the outcome cannot be predicted (Bibikova et al. 2002, Sander and Joung 2014). The generation of InDels within a mutated genomic region may also restore gene function through the correction of disease causing mutations (Long, McAnally et al. 2014). Therefore, the engineered nucleases to be described in the next sessions, Zinc-finger nucleases (ZFNs), Transcription Activator-Like Effector Nucleases (TALENs) and CRISPR-Cas systems, allowed the generation of transgenic organisms in a more efficient way and have introduced a new era in gene function analysis.

\section{PROTEIN-GUIDED ENGINEERED NUCLEASES}

The use of ZFNs (Zinc-Finger Nucleases) and TALENs (Transcription Activator-Like Effector Nucleases) facilitated the generation of transgenic animals. In comparison to the endogenous DNA break events, the activity of the engineered nucleases may increase the frequency of DSBs in a specific region in about 10,000-100,000 (Moehle et al. 2007). In addition to ZFNs and TALENs, other valuable tools for genome editing have been 

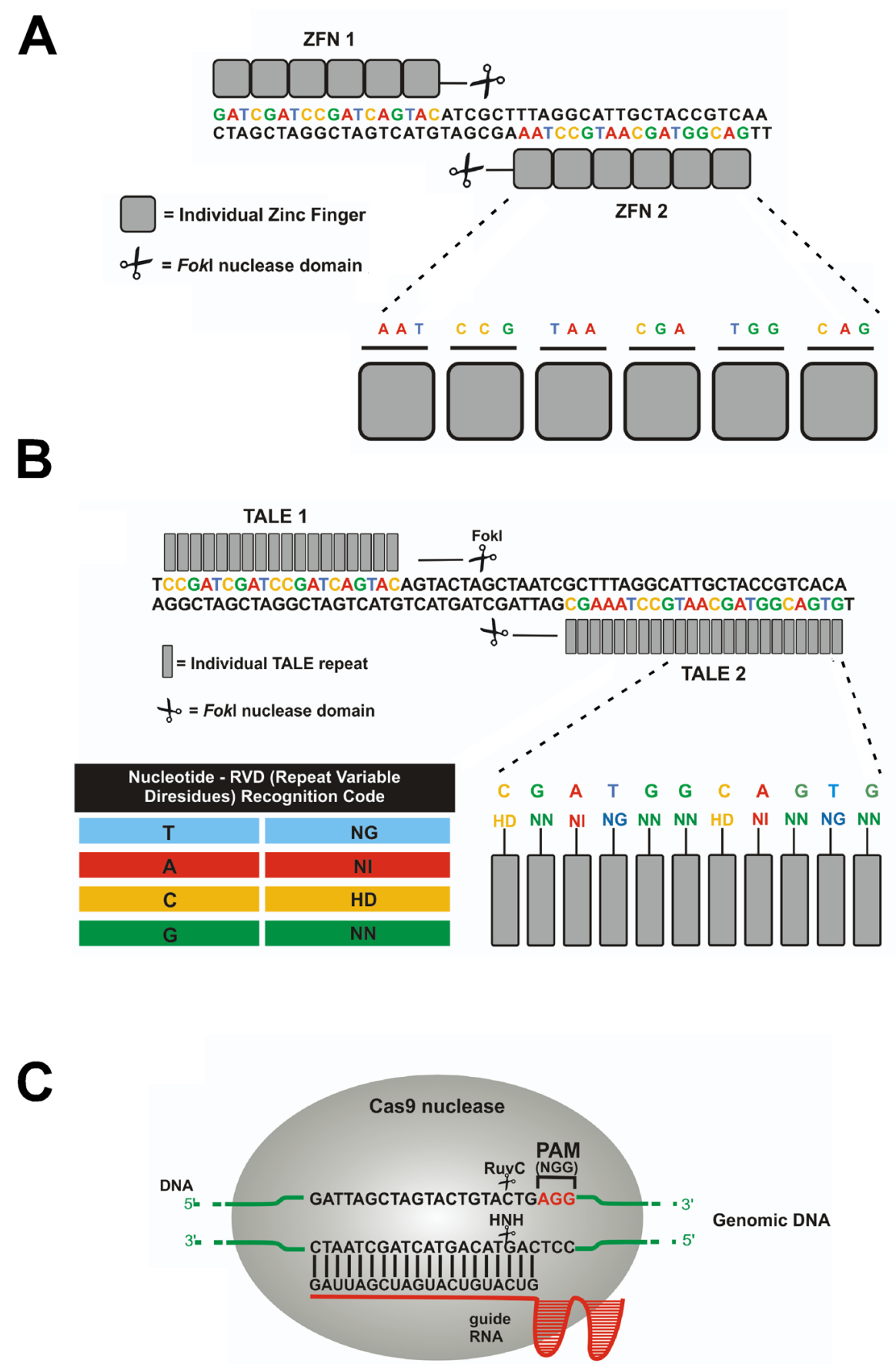

Figure 2 - Molecular mechanisms of DNA recognition: ZFNs, TALENs and CRISPR/Cas9: (A) Illustration of a ZFN pair bound to DNA sequence on opposite strands. In this case, each individual zinc finger domain (gray square) binds to a nucleotide triplet. (B) Illustration of a TALEN pair bound to DNA sequence on opposite strands. Note that each individual TALEN module (gray rectangle) is bound to a specific nucleotide, through interactions of two amino acid residues (RVD - repeat variable diresidues) and the nucleotide (inset in TALEN 2). The RVD-nucleotide recognition code is shown on the left. The FokI DNA cleavage domains of each ZFN (A) or TALEN (B) are juxtaposed and present a spacer region in between them. (C) The CRISPR/Cas9 recognition system consists of a guide RNA (gRNA, red) transcript and the Cas9 nuclease. The gRNA requires an adjourning NGG sequence (PAM) for Cas9 recognition and directs DNA cleavage through base pair complementarity. RuvC and HNH nuclease domains of Cas9 create DSBs at the genomic target site (green). 
developed (e.g. meganucleases and transposons), but these are not in the scope of this review.

One of the biggest limitations imposed by restriction endonucleases was the small size of the DNA site to be recognized, what hampered their use when working with larger DNA sequences due to cleavage activity in multiple sites. Also, most restriction enzymes present DNA binding and cleavage activity within the same domain, limiting their targeting capability (Lanio et al. 2000). However, a few of them have separate binding and cleavage domains, such as FokI. In order to increase the possible binding sites for restriction enzymes, Dr. Srinivasan Chandrasegaran and colleagues envisioned an approach of linking DNA binding region of homeodomain transcription factors to the cleavage domain of FokI. The resultant artificial nuclease contained a DNA binding homeodomain fused to FokI nuclease, being able to cleave DNA sequences nearby homeodomain-binding sites (Kim and Chandrasegaran 1994). Later on, this same group assembled the first ZFNs (Kim et al. 1996), paving the way to genome tailoring at custom sites.

ZFNs are chimeric proteins composed of a modular array of Cys2-His2 DNA-binding zinc fingers fused to a FokI nuclease domain (Kim et al. 1996, Bibikova et al. 2001, Urnov et al. 2010). These modular arrays are usually composed of 3-6 zinc fingers that recognize three nucleotides each, providing DNA binding specificity to the nuclease (Greisman and Pabo 1997, Wolfe et al. 2000, Maeder et al. 2008, Ramirez, Foley et al. 2008) (Figure 2A). A pair of ZFNs must be designed to target a given genomic region, since the FokI nuclease domain requires dimerization to work (Bitinaite et al. 1998). Each zinc finger array binds to close DNA regions, on opposite strands, so that a DSB is induced in a specific genomic site (Fig. 2A). The repair of the DSB may lead to DNA insertion, deletion, inversion, point mutations or translocations, depending on the targeting strategy used and the DNA repair pathway chosen by the cell (Fig. 3).
ZFNs can be assembled by merging previously described individual zinc fingers characterized for specific nucleotide triplets. However, the resulting ZFNs may not necessarily bind to the expected sequence (Ramirez et al. 2008). Efficient DNA recognition by ZFNs is highly dependent on the position of the zinc fingers in the array and on the 3-dimensional conformation of the entire engineered protein (Ramirez et al. 2008). This aspect led to the extensive research on the development of methods for the selection of functional ZFNs. Recently, new platforms for ZFN assembly arose (Maeder et al. 2008, Sander et al. 2010, Bhakta et al. 2012), however commercial custom-made ZFNs are still the quickest and safest design option.

TALE proteins were described as key players during plant infection by bacteria of the genus Xanthomonas. These secreted bacterial proteins can bind specific DNA promoter regions of the plant cells regulating host gene expression (Romer et al. 2007). TALEs are modular proteins composed of TALE repeats (34 amino acids each) that contain two hypervariable amino acid residues called RVDs (repeat variable diresidues) at positions 12 and 13. These variable residues determine a surprisingly simple code of DNA binding specificity: the combination of these two amino acid residues dictates the specific binding to one nucleotide (Boch et al. 2009, Moscou and Bogdanove 2009) (Fig. 2B).

Similar to ZFNs, TALENs were developed by fusing the FokI endonuclease domain with an array of TALE repeats. TALEN assembly is much less problematic in comparison to ZFN, although some difficulties are present. Different from ZFNs, modular assembly of TALE repeats results in the predicted DNA binding pattern. On the other hand, cloning steps to generate the desired TALEs can be challenging due to the high DNA sequence homology between the different repeats. However, advances in cloning systems are helping to overcome these difficulties (Engler et al. 2008). As an example, libraries of TALENs targeting most 


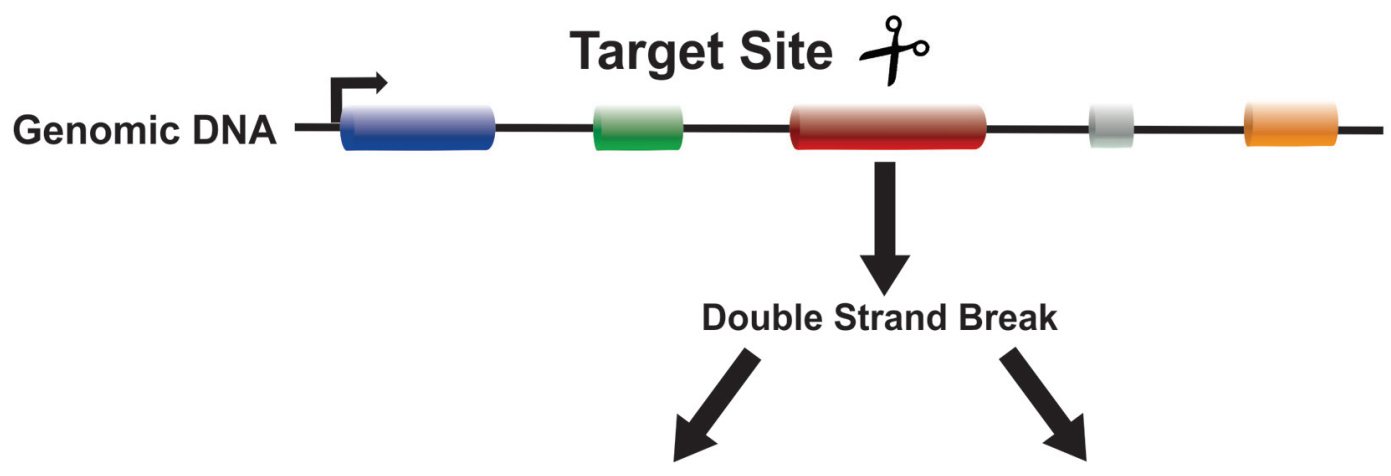

Repaired by NHEJ

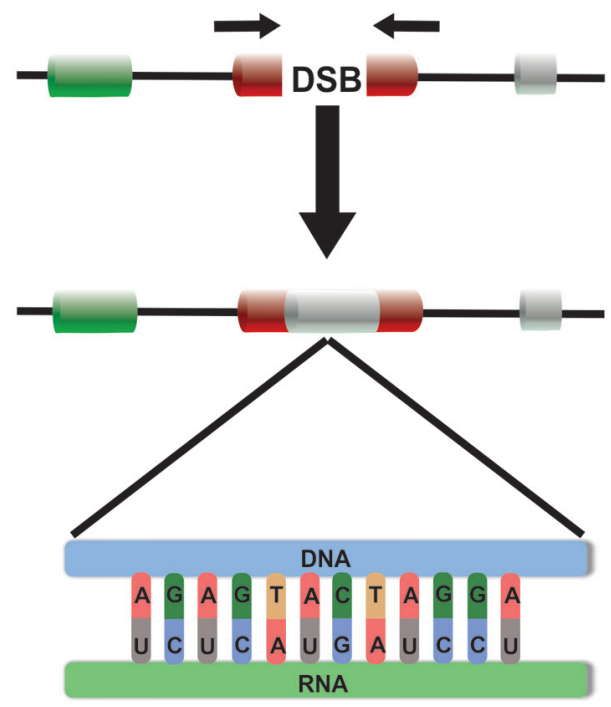

Serine Histidine Aspartate Proline

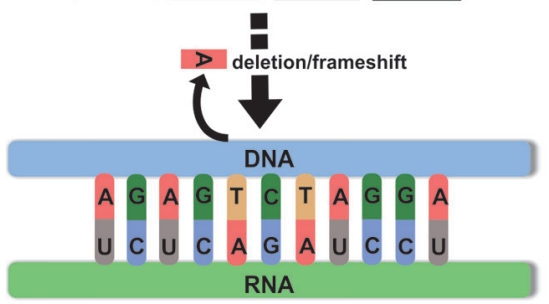

Serine -Glutamine-Isoleucine
Repaired by HDR
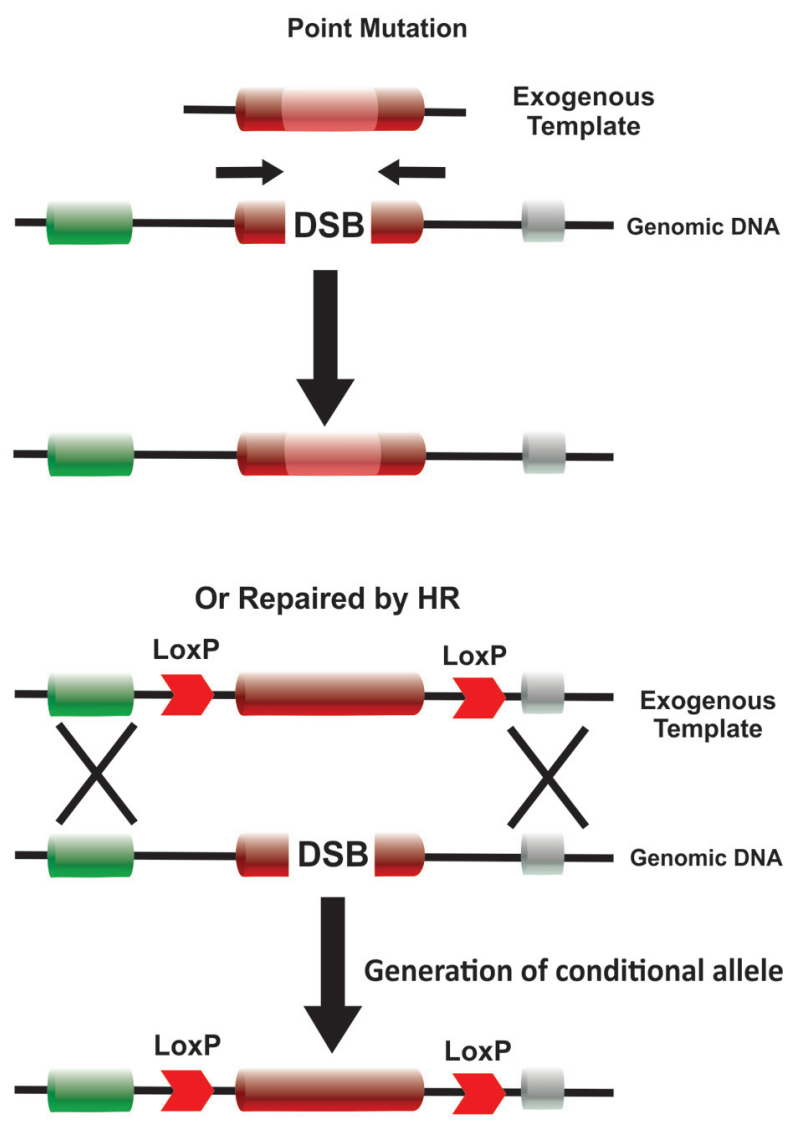

Figure 3: Nuclease-induced genome editing: modes and applications: Custom target nucleases (ZFNs, TALENs and CRISPR/ Cas9) stimulate DSBs at the genomic region of interest. The cell can choose between different DNA repair pathways: nonhomologous end joining (NHEJ), homology-directed repair (HDR) or homologous recombination. In the absence of a homology repair template, the endogenous repair machinery may introduce InDels (insertions/deletions) via error-prone NHEJ, which can result in a frameshift downstream of the DSB. To produce animals with defined editing, an exogenous template carrying a modified sequence (e.g. point mutation or LoxP sites) flanked by homology arms is used to trigger either HDR or HR. 
of human coding-genes and microRNAs were recently developed (Kim et al. 2013a, b).

The extent of off-target effects of ZFNs and TALENs was shown to vary between experimental designs (Gabriel et al. 2011). Generally, when using ZFNs and TALENs, it is desirable to give these nucleases a narrow time-window to work within the cell. A common approach is to directly deliver the mRNAs encoding these proteins into the cell, in order to quickly and transiently generate the nucleases that will induce sequence-specific DSBs. This avoids unspecific cleavage events that may happen due to prolonged nuclease presence (e.g. integrated transgenes coding ZFNs or TALENs). Another option for transient expression is the use of non-integrating viral vectors. In addition, a recent report indicated that ZFNs may enter the cells by itself. Although this requires previous purification of each nuclease, it has the advantage of reducing off-target effects due to the rapid degradation of the nuclease inside the cell (Gaj et al. 2012).

By using direct injection of ZFN mRNAs into one-cell stage embryos, the first ZFN-based transgenic mice were generated (Carbery et al. 2010). In this study, either Mdr1a, Jag1 or Notch3 genes were targeted. Around $20-75 \%$ of pups presented insertions or deletions in the coding sequence as a consequence of the activation of the NHEJ pathway. Notably, most of the founder mice generated were mosaic for the genomic alterations, indicating that ZFN activity primarily occurred after first cell division. The authors reported successful transmission of the modifications to the F1 generation. Later, another study co-injected a one-cell stage embryo with ZFN mRNA targeting the ROSA26 locus and a vector carrying the $\beta$-galactosidase gene flanked by ROSA26 locus homologous sequences (Meyer et al. 2010). This resulted in the integration of the $\beta$-galactosidase in the endogenous ROSA26 locus, providing the first indication that, following fertilization, ZFNinduced DSB may activate distinct DNA repair pathways: either the mutation-inducing NHEJ or the homology-directed repair (HDR) (Fig. 3).
Additionally, the authors reported efficient gene targeting in $1.7-4.5 \%$ of co-injected mouse zygotes.

Despite the fact that ZFNs emerged earlier than TALENs as a tool for genome editing, the first transgenic mice created using each technology appeared relatively at the same time. This may be the consequence of the technical challenges imposed by ZFN design and suggests that, for future applications, TALENs will be preferred given its easier assembly. The first transgenic mouse created by TALEN-mediated genome editing method was reported in 2013 (Sung et al. 2013). Cytoplasmic injection of TALEN mRNAs targeting either Pibfl or Sepwl genes in mouse pronuclear-stage embryos resulted in TALEN activity already at the one-cell stage. It was suggested that the presence of mosaicism in a minority of the founders was a consequence of TALEN activity at the late onecell stage after DNA duplication. Another work reported that the majority of founder mice present mosaicism, indicating that TALENs' activity after first round of cell division may vary (Qiu et al. 2013). These studies provided evidence that following DNA damage induced by TALENs, the fertilized egg may induce the NHEJ repair pathway and that these mutations were transmitted through the germ line. HDR-mediated incorporation of exogenous templates following TALENs-induced DSBs was also reported (Sommer et al. 2014).

Of great relevance for the mouse transgenesis field is the fact that only few strains of mouse ES cells have been successfully cultured, limiting the number of strains used to generate transgenic mice (Kawase et al. 1994). ZFNs and TALENs methods are poised to overcome this limitation allowing the generation of transgenicmice of diverse backgrounds without time-consuming backcrossing. Notably, the generation of mouse knockouts for Y-linked genes using traditional gene targeting methods has been quite unsuccessful, mainly due to $\mathrm{Y}$ chromosome structural particularities. In the mouse, most of the knowledge about the in vivo function of Y-linked genes has come from spontaneous mutations or 
A

\section{Cre-dependent Cas9 targeting vector}
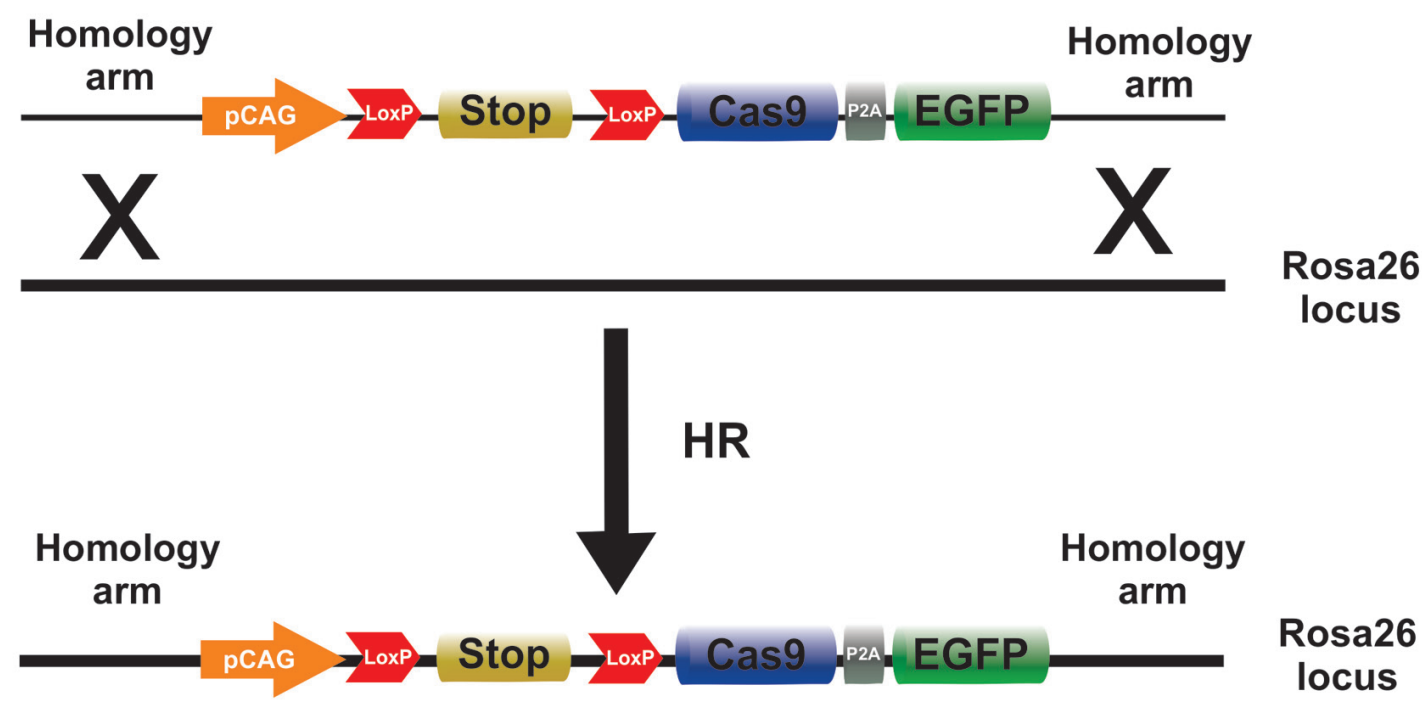

$\mathbf{B}$

\section{Cre-dependent genome editing}

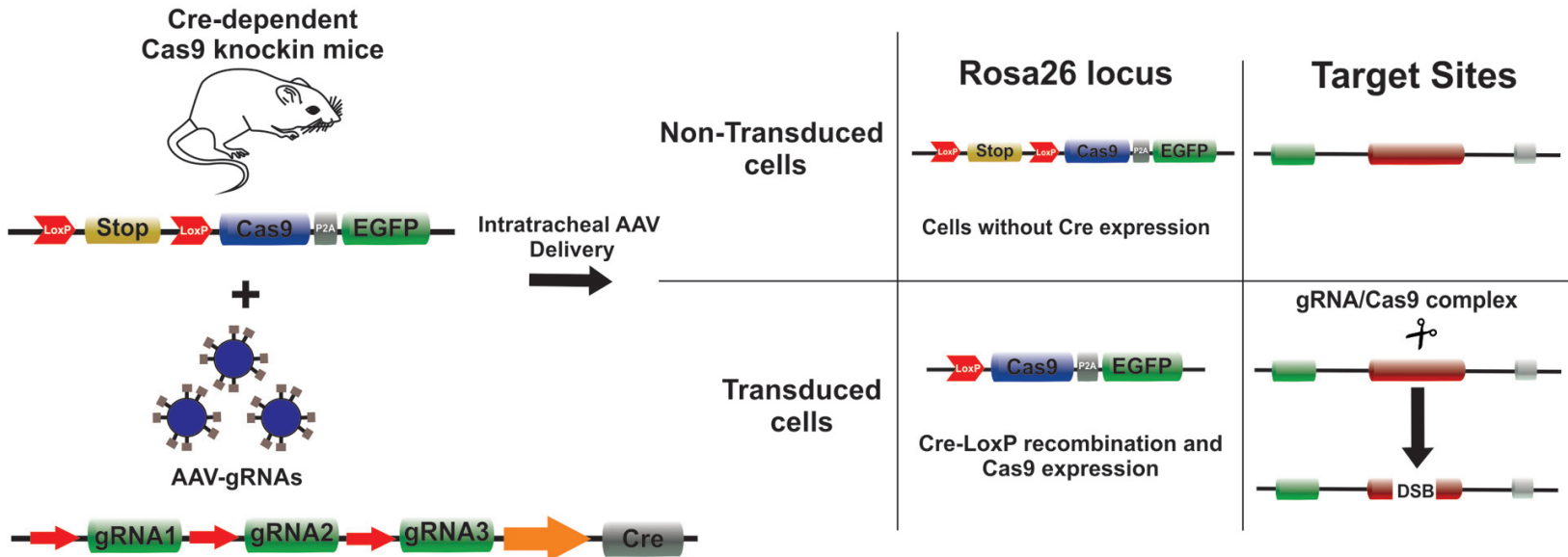

Figure 4: Generation and applications of the Cre-Dependent Cas9 mouse knockin: (A) Illustration of the Cre-dependent Cas9 Rosa26 targeting vector. Exogenous template contained ubiquitous CAG promoter (pCAG), LoxP-Stop-LoxP cassette (LSL), Cas9 nuclease gene, self-cleaving P2A peptide and the reporter gene (EGFP) flanked by two homology arms. The transgene expression cassette was introduced through homologous recombination into the Rosa26 locus. (B) Spatial and temporal control of multiplex CRISPR/Cas9-mediated genome editing. A single AAV vector integrating guide RNAs (gRNA) for three different genes as well as a Cre recombinase expression cassette was delivered into Cre-dependent Cas 9 mice. In this experiment, Cre recombinase activity on transduced cells lead to excision of LSL and Cas9 expression. Cas9 nuclease activity directed by gRNAS introduce DSB at the target sites of interest. In constrast, genomic DNA of non-transduced cells remain intact, since Cas 9 expression and activity relies on Cre recombinase and gRNAs, respectively. 
non-targeted induced mutations in Y-linked loci (Lovell-Badge and Robertson 1990, Mazeyrat et al. 2001). TALEN technologies allowed researchers to induce targeted mutations in Y-linked genes (e.g. Sry and Uty) (Wang et al. 2013) and multiplexed genome editing (Li et al. 2014).

Although both ZFNs and TALENs brought advances for transgenic mice generation, drawbacks presented by whole-embryo knockin or knockout mice are still possible. As explained, some cases of embryonic lethality or organ malformation due to non-autonomous effects can be prevented by cell type/tissue-specific gene inactivation. Therefore, applications that combine engineered nucleases with other transgenesis tools, such as the Cre-LoxP system, can be used to reach tissue- and spatialspecificity in gene inactivation (Bedell et al. 2012, Brown et al. 2013) (Fig. 4). Another way to restrict the action of the nucleases to specific tissues is through delivery of ZFN and TALEN DNA or mRNA by electroporation as performed in the ascidian Ciona intestinalis (Treen et al. 2013).

The potential of ZFNs- and TALENs-based genome edition approaches to generate mouse models of human diseases is only starting to be explored (Perez et al. 2008, Li et al. 2011, Anguela et al. 2013). For instance, in a mouse model of haemophilia $\mathrm{B}$, which carries a coagulation factor IX (F9) mini-gene that phenocopies the human mutation, delivery of ZFNs to the liver of adult mice along with a donor DNA template containing a region of wild-type F9 gene, stimulated gene replacement ( $\mathrm{Li}$ et al. 2011). This procedure resulted in haemophilia recovery, as indicated by the reestablishment of the normal clotting times. Interestingly, treated animals maintained the functional recovery even following partial hepatectomy, indicating that the recipient quiescent cells replicated normally. Another example of experimental models of liver diseases was the generation of a murine model of hepatocellular carcinoma. In this study, TALENs delivery to the liver of healthy mice induced mutations in genes associated with liver tumorigenesis (Zhang et al.
2014). Delivery of TALEN mRNA to fertilized mouse oocytes carrying a retinal degeneration phenotype linked to the Crb1 (rd8) allele led to gene correction and generation of phenotipically normal mice (Low et al. 2013). Advances in the mitigation of off-targets effects of both ZFNs and TALENs point to promising advances towards the translation of these technologies to the clinic for a number of diseases (Miller et al. 2007, Szczepek et al. 2007, Doyon et al. 2010, Anguela et al. 2013).

Another envisioned approach to treat human disease using these nucleases was the ZFN-mediated mutation of the CCR5 gene, which codifies a HIV co-receptor. This resulted in CD4+T cells survival after HIV infection in vitro (Perez et al. 2008). When transplanted into the mouse, CD4+T edited cells were able to resist viral infection and populate murine tissues (Holt et al. 2010). Currently, a ZFNbased clinical trial to control AIDS is recruiting patients for a phase 2 study. ZFN-based therapies for diabetic neuropathy and glioblastoma are also in clinical trials. In vitro correction of mutations linked to disease, such as sickle-cell anemia (Sebastiano et al. 2011), amyotrophic lateral sclerosis (Kiskinis et al. 2014) and $\alpha 1$-antitrypsin deficiency (Yusa et al. 2011) have been achieved through ZFN-based methods or as in the case of epidermolysis bullosa (Osborn et al. 2013) through the use of TALEN technology.

\section{RNA-GUIDED NUCLEASES: CRISPR/CAS9}

As mentioned, a challenging aspect of the ZFN and TALE protein-guided approaches is the requirement to design new modular DNA-binding proteins for each gene target. It became clear that engineering nucleases guided by alternative modes of DNA recognition would simplify genome editing. At this point, the RNA-guided endonuclease technology CRISPR/Cas9 is established as the less timeconsuming method of reduced cost that allows targeting of multiple DNA sites. These features brought the possibility of transgenesis at a system 
level one step closer (Cong et al. 2013, Mali et al. 2013).

The development of the Cas 9 endonuclease for genome editing became possible due to more than a decade of research on the biological function of the repetitive elements now known as CRISPR (clustered regularly interspaced short palindromic repeats). A study on the chromosomal DNA segment that contains iap gene in E. coli, an enzyme responsible for isozyme conversion of alkaline phosphatase, reported an unusual series of repeat sequences (direct repeats) interspaced by variable sequences (spacers) (Ishino et al. 1987). Sequencing of other microbial genomes revealed that these interspaced repeat sequences were present across many species ( $40 \%$ of sequenced bacteria and $\sim 90 \%$ of archaea) and these were classified as a unique family of clustered repeat elements (Mojica et al. 2000).

Despite the detailed mapping and annotation of CRISPR loci, their role remained elusive. Some suggested that the spacers descend from foreign genetic elements, such as bacteriophages (Bolotin et al. 2005, Mojica et al. 2005, Pourcel et al. 2005). In 2007, Horvath and colleagues demonstrated that CRISPR spacers dictated target specificity through base-pair complementarities between nucleic acids, while Cas enzymes were required for the acquisition of new spacer sequences and defense from phage infection (Barrangou et al. 2007). This was the first experimental evidence for the biological significance of a type II CRISPR system as an adaptive immune mechanism. Subsequent CRISPR discoveries unraveled details of each CRISPR system and elucidated the components required for engineering a simple RNA-programmable endonuclease for genome editing.

The type II CRISPR/Cas9 system is composed of an array of small CRISPR RNAs (crRNAs), auxiliary trans-activating crRNA (tracrRNA) and a significantly reduced number of nuclease associated with the CRISPR locus (CRISPR associated - Cas). Cas9 is the only enzyme within the cas gene cluster that mediates DNA cleavage (Garneau et al. 2010). TracrRNA hybridizes with crRNA, this dual RNA hybrid, together with Cas9 and endogenous RNase III, is required for processing the CRISPR array transcript into mature crRNAs (Deltcheva et al. 2011). The small crRNAs containing individual spacers require an adjourning NGG sequence known as the protospacer adjacent motif (PAM)

TABLE I

Comparison of ZFN, TALEN and CRISPR/Cas9 engineered nucleases.

\begin{tabular}{lccc}
\hline & ZFN & TALEN & CRISPR/Cas9 \\
\hline Recognition mode & Protein-DNA & Protein-DNA & RNA-DNA \\
Recognition site & $9-18 \mathrm{bp} \mathrm{x} 20 \mathrm{bp}$ \\
Nuclease type & FokI & $10-20 \mathrm{bp} \mathrm{x} 2$ & Cas9 \\
Size & $\sim 1 \mathrm{~kb} \times 2$ & FokI & $\sim 4.2 \mathrm{~kb}(\mathrm{Cas} 9)+0.1 \mathrm{~kb}(\mathrm{gRNA})$ \\
Permissive mismatches & Not known & $\sim 3 \mathrm{~kb} \times 2$ & 3 \\
Multiplex targeting & Very Limited & Limited & Possible (e. g. 8 alleles) \\
Sensitivity to DNA methylation & Sensitive & Sensitive $* *$ & Non-Sensitive \\
\hline
\end{tabular}

* reported to greatly reduce cleavage activity of the TALEN (Meckler et al. 2013).

** can be overcomed since TALEs recognize methylated citosines as thymines in the major groove. 
site for Cas9 recognition (Deveau et al. 2008) (Fig. 2C).

By 2013, various groups began to harness the CRISPR system for genome edition (Cong et al. 2013, Mali et al. 2013). The endogenous bacterial crRNA and tracrRNA were engineered into a single chimeric guide RNA (gRNA) transcript that combines the targeting specificity of the crRNA with the scaffolding properties of the tracrRNA. When the gRNA and the Cas9 were expressed in a cell, the Cas9 HNH and RuvC-like nuclease domains cleave the complementary and non-complementary strands (Fig. 2C). The DSB elicit an error-prone DNA repair pathway (Jinek et al. 2012). The guide sequence within these CRISPR RNAs, that typically derives from phage sequences (Barrangou et al. 2007), can be easily replaced by a sequence of interest to retarget the Cas9 nuclease. The use of a small gRNA to target DNA dramatically facilitated site-specific genomic modifications.

As expected, one major concern when using CRISPR/Cas9 system is the occurrence of high off-target mutagenesis, since gRNA-DNA target binding tolerate up to three mismatches (Cradick et al. 2013, Pattanayak et al. 2013). In order to improve specificity without compromising ontarget cleavage efficiency, Cas9 was converted to a nicking enzyme. Individual nicks in the genome are repaired with high fidelity, and simultaneous nicking by using a pair of gRNAs is necessary to effectively introduce targeted DSBs. In this case, the increase in the number of specifically recognized bases in the target site minimized the off-target activity (Ren et al. 2013). Specificity can be further tuned by titration of CRISPR/Cas9 components and reduction of the regions responsible for target complementarity (spacer region) (Hsu et al. 2013, $\mathrm{Fu}$ et al. 2014). Truncated gRNAs composed by shorter spacer regions ( $<20$ nucleotides) display less non-specific cleavage activity mutagenesis without compromising on-target activity (Fu et al. 2014). Even without undesired DSBs, a screening process is required, since the InDels induced by NHEJ repair pathway are still random.
The CRISPR/Cas9 technology was rapidly applied for gene modification in a variety of experimental model systems (Caenorhabditis elegans (Dickinson et al. 2013), Drosophila melanogaster (Gratz et al. 2013), Arabidopsis thaliana (Jiang et al. 2013), Rattus norvegicus (Ma et al. 2013), Danio rerio (Hwang et al. 2013), and Macaca fascicularis (Niu et al. 2014) due to advantages over other genome editing methods (Table I) (Meckler et al. 2013). Cas9 and gRNA can be microinjected into embryos through the use of plasmid expression vectors or in vitro transcribed RNA (Hsu et al. 2013, Fei et al. 2014, Fujihara and Ikawa 2014, Niu et al. 2014). However, generation of knockin lines expressing Cas9 nuclease, as done for mice and Drosophila, provides a straightforward method to optimize efficiency of mutagenesis and recovery of injected animals (Ren et al. 2013, Platt et al. 2014).

Multiplexed gene editing at unprecedented scale through a battery of short gRNAs rather than a library of large proteins is a major advantage of this approach (Cong et al. 2013, Jao et al. 2013, Mali et al. 2013, Wang et al. 2013, Ma et al. 2014, Ma et al. 2014, Xing et al. 2014). For example, simultaneous disruption of functionally redundant genes from the same gene family (Tet1, 2, 3, Sry, Uty - 8 alleles) was accomplished in mouse ES cells. These results showed that out of 96 clones screened, $10 \%$ carried mutations in all eight alleles of the five genes (Wang et al. 2013). Thus, CRISPR/ Cas9 has the potential to circumvent the need of sequential recombination and intercrossing of lines to generate animal models carrying mutations in multiple genes.

As described for ZFNs and TALEN (Bedell et al. 2012, Brown et al. 2013), conditional gene modification that allows temporal and spatial control of gene inactivation (Cre-Lox system) was also achieved using Cas9-triggered HR (Yang et al. 2013, Lee and Lloyd 2014, Ma et al. 2014). For example, to generate rats with LoxP-containing alleles, Cas9 and a single gRNA designed to target (cytosine-5)methyltransferase 1 (Dnmt1) were injected with an 
exogenous template containing the $\operatorname{Lox} P$ sites and homologous sequences flanking the DSB (Fig. 4). A circular donor vector containing exon 1 flanked by 2 LoxP sites and 2 homology arms of $\sim 800$ bp each was used as a template to repair the DSB by HR and produce animals with targeted integration (Ma et al. 2014). Two out of 12 founder rats contained floxed exon 1 on the same allele and one of them presented a biallelic modification. Other four rats only carried NHEJ-mediated mutations (Ma et al. 2014). Moreover, because the characterization of gene expression relies on the availability of highquality antibodies, Cas9-triggered HR can also be explored to introduce tags or reporter transgenes to endogenous locus (Yang et al. 2013, Krentz et al. 2014). This technique has proven efficient to create both reporter and conditional lines in a single step.

Apart from the fact that the generation of transgenic strains can take several months, delivery of Cas9 nuclease and gRNAs into developing and adult organisms allows phenotyping of controlled perturbation in the 'F0' (Liu et al. 2014, Platt et al. 2014, Stolfi et al. 2014, Straub et al. 2014, Wang et al. 2014). CRISPR/Cas9-mediated knockout is more efficient than controlled silencing of targeted mRNA via RNA interference (RNAi) or morpholino (Harrison et al. 2014, Schulte-Merker and Stainier 2014). Moreover, it enables targeting of non-coding regions, such as promoters, enhancers, splice site sequences and mRNA 5' and 3' untranslated regions. For example, Wang and collaborators interrogated whether a putative enhancer (B108) is required for Blimp1 expression during retinogenesis through in vivo electroporation of a vector plasmid encoding both Cas9 and a gRNA. The transcription factor Blimp1 is a key component of the gene regulatory network that determines whether a retinal progenitor cell becomes a rod photoreceptor or a bipolar interneuron. Deletion of the genomic B108 enhancer by CRISPR/Cas9 recapitulated Blimp 1 conditional knockout phenotype with a relative increase in the proportion of bipolar cells, demonstrating that B108 is a cis-regulatory module necessary for proper Blimp1 expression in the developing retina. More importantly, they determined that CRISPR/Cas9 effectively allows genomic edition in heterogeneous somatic tissues in vivo (Wang et al. 2014).

Development of plasmids or mouse lines with Cas9 expression under the control of tissue-specific promoters/enhancers will further increase the spatial and temporal control over genome editing (Liu et al. 2014, Xue et al. 2014). In mice, the establishment of a Cre-dependent Cas9 knockin strain facilitates in vivo applications to somatic tissues (Platt et al. 2014). In brief, ES cells were transfected with a targeting vector containing a constitutive promoter, a LoxP-stop-LoxP (LSL) cassette and the Cas9 coding sequence linked via P2A peptide to an EGFP. Therefore, Cas 9 expression depended on the excision of the LSL cassette by Cremediated recombination (Fig. 4A). ES cells that incorporated the transgene cassette by homologous recombination were subsequently implanted in blastocysts using the standard procedures to generate the Cre-dependent Cas9 knockin mice (Platt et al. 2014). This strategy combines the tissue-specificity driven by Cre recombinase with Cas9 genome editing capabilities, what allows modeling of multigenic human diseases. Platt and colleagues used a single AAV-vector composed of three distinct gRNAs and Cre recombinase coding sequence to target three frequently mutated genes in lung cancer (p53, Lkb1, and K-Ras) (Fig. 4B). The viruses were introduced directly into the trachea of Cre-dependent Cas9 mice. Cre recombinase activity on transduced cells lead to excision of the LSL and induction of Cas9 expression. Then, Cas9 nuclease activity directed by gRNAs introduced DSB at the three target sites of interest (Fig. 4B). In contrast, genomic DNA of non-transduced cells remained intact, since Cas9 expression was not induced due to the absence of Cre-mediated recombination of the LSL (Fig. 4B). In this study, Cas9-induced mutations in p53, Lkb1, and K-Ras were sufficient to induce multiple tumor nodules in the lung. This was an excellent example that the traditional methods of transgenesis (HR), the 
Cre-LoxP system and genome edition by nucleases are not mutually exclusive. In fact, they can be combined to achieve state-of-the-art functional analysis of multiple genomic regions.

The described revolution in genomic editing possibilities offered new ways to expand the range of studied organisms, including species where gene targeting was not yet available (Daimon et al. 2013, Flowers et al. 2014, Guo et al. 2014, Niu et al. 2014). For instance, CRISPR/Cas9 technology allowed functional characterization of the regenerative capacity of salamanders, the only tetrapod that regenerates the spinal cord and all cell types of the limb at an adult stage. Researchers addressed for the first time the regeneration phenotype in the axolotl by deleting a key neural stem gene (Sox2) (Fei et al. 2014). Although Sox2-CRISPR RNAs injection into single-cell fertilized eggs had no effect on spinal cord organization, upon tail amputation, cell proliferation did not increase in the spinal cord, preventing the regrowth of this tissue in the regenerating tail (Fei et al. 2014). These studies in salamanders may shed light on the limited regenerative abilities of other organisms.

CRISPR-Cas9 methods also have a potential utility to either treat or prevent human genetic disorders (Schwank et al. 2013, Li et al. 2014, Long et al. 2014, Wu et al. 2014, Yin et al. 2014). As proof of concept, this system was deployed in vivo to correct a homozygous point mutation of fumarylacetoacetate hydrolase (Fah) in a mouse model of hereditary tyrosinemia type I (HTI) (Yin et al. 2014). FAH deficiency causes accumulation of toxic metabolites, such as fumarylacetoacetate in hepatocytes, resulting in severe liver damage. In adult mice, hydrodynamic tail vein injection of CRISPR-Cas9 system components and a short DNA repair template for gene correction resulted in initial expression of the wild-type Fah protein in $\sim 1 / 250$ liver cells. Due to survival advantage, Fah-positive hepatocytes expanded and rescued the body weight phenotype of the adult mice (Yin et al. 2014). Therapeutic strategies through genome editing look promising; however, safety issues cannot be underappreciated. One must consider possible immune responses against the bacterial nuclease as well as off-target nuclease activities.

Cas9 targeting has become a versatile tool for engineering biology due to its high efficiency as a site-specific nuclease and the possibility for multiplexed modifications. So far, CRISPR/Cas9 system has broadened the repertoire of target sites and biological applications from basic research to biotechnology.

\section{CONCLUSIONS}

\section{ADVANCES IN THE GENERATION OF TRANSGENIC MiCE}

In the past, most methods employed for genetic alterations were restricted to model organisms, such as mice, whose ES cells could be manipulated at endogenous genomic loci via homologous recombination(HR). Historically, the low frequency of desired recombination events ( 1 in $10^{6}-10^{9}$ cells), characteristic of traditional transgenesis methods (Capecchi 1989, Capecchi 2005), presented considerable pitfalls for systems level applications (e.g. targeting multiple genetic pathways). For instance, more than 15,000 Drosophila genes and 30,000 mouse genes have been annotated (Adams et al. 2000, Waterston et al. 2002) and several lossof-function mutants have been generated, however many genes still lack functional characterization (Bradley et al. 2012, Koscielny et al. 2014). Traditional methods allowed great advances in understanding gene function in vivo, but the generation of transgenic animals is a laborious and time-consuming process. Engineered nucleases are turning this task much more precise and efficient, by allowing direct genetic modification of target loci, increasing the rate of site specific DSBs and thus improving transgenesis by homologous recombination. Curiously, somehow the modern methods resemble the first attempts to generate transgenic mice, since genetic manipulation occurs directly in the zygote, eliminating the need of ES cell culture and selection steps. 


\section{COMPARING THE NUCLEASES}

A comparison of the features of ZFNs, TALENs and CRISPR/Cas9 is summarized in Table I. In general, the RNA-guided nuclease CRISPR/Cas9 is advantageous over protein-guided nucleases. The design process is easier, as CRISPR/Cas9 does not require different proteins for each target and eliminates laborious cloning steps. Moreover, CRISPR/Cas9 is much more amenable for multiplex applications and does not present sensitivity to DNA methylation, being the method of choice if one plans to target a GC-rich region. Although considerable efforts into increasing the specificity of these nucleases have been made (Miller et al. 2007, Szczepek et al. 2007, Doyon et al. 2010), additional work is required to precisely detect the off-target events (Gabriel et al. 2011). New methodologies to map off-target activity are arising, such as spontaneous integration of Integrase-Defective Lentiviral Vectors (IDLV) in DSBs (Kim et al. 2013, Wang et al. 2015) and targeted sequencing of translocated DSB regions (Frock et al. 2015). Regarding specificity, TALENs might be considered a favorite, since reports indicate that one mismatch in the binding site may impair TALE binding. In addition, to avoid DNA cleavage in undesired locations, TALENs have been engineered to prevent homodimerization and Cas9 to work as a nicking enzyme.

\section{ADVANCES IN NON-MODEL ORGANISMS}

The study of genome function in non-model animal species has been widely hampered by the lack of an efficient and stable system to promote genetic lossof-function. Although, in principle, homologous recombination could be used to modify the genome of any animal species, ES cell targeting would be required to generate whole-animal genetic modifications. Challenges in establishing ES cell culture for a wide range of models hindered the production of transgenic non-model animals. RNAi technology brought substantial advances to understanding and interfering with regulatory networks in non-model species. However, RNAi often produces multiple off-target effects and provides transient loss-of-function, making it difficult to analyze long-term effects of gene inactivation. Also, RNAi is a gene-oriented technology, not allowing targeting of genomic regulatory regions. Engineered nucleases offer a remarkable opportunity to study the function of genomic loci in non-model organisms. The current vision is to turn any organism into a genetic trackable model, the same way the scientific community has been able to easily engineer $S$. cerevisae and E. coli.

ADVANCES IN SPATIAL AND TEMPORAL CONTROL

Although a big number of SSR enzyme lines have been developed, one of the limitations for their use is the relatively restricted number of cell type specific expression transgenes available. Recent developments on GFP binding proteins may improve in vivo manipulation of SSR enzymes. Cepko and colleagues established a system in which the activation of a transgene expression depends on the presence of GFP. In brief, two different proteins recognize distinct portions of GFP: one fused to a DNA binding domain and the other to the transcriptional activator p65. When GFP brings these proteins together, gene expression is triggered. Using this technique, authors demonstrated that Cre expression can be restricted to GFP expressing cells (Tang et al. 2013). This methodology can bypass the need to generate new cell/tissue-specific Cre lines, given the huge number of cell typespecific GFP lines already available. Other possible application is the cell type specific control of ZFN, TALEN or Cas9 expression.

\section{EPIGENOME EDITION}

Some of the exciting possibilities offered by the advances in nuclease engineering might go beyond genome editing applications. The fusion of DNA binding modules (zinc-finger proteins or TALEs) to different effector domains points 
to a new era of synthetic biology in complex systems. One of the most astounding possibilities is to "edit the epigenome" by, for example, introducing or removing specific postranslational histone modifications and DNA methylation at target loci (Maeder et al. 2013, Mendenhall et al. 2013). TALEs fused to a light-responsive domain were also used to control gene expression using optogenetics in both primary neurons in vitro and in the mouse brain in vivo (Konermann et al. 2013). Another novel application derived from TALENs is the visualization of chromatin dynamics through live imaging, using a TALE domain fused to a monomeric form of GFP (Miyanari et al. 2013). Furthermore, the CRISPR/Cas9 system has also been engineered to allow flexible recruitment of desired perturbations, such as transcriptional activation, to a locus of interest $\mathrm{Xu}$ and Bestor 1997, Beerli et al. 2000, Konermann et al. 2013, Maeder et al. 2013, Mendenhall et al. 2013).

\section{RESUMO}

Tecnologias de modificação do genoma são ferramentas poderosas para a biologia molecular e áreas afins. Avanços na transgênese animal e em tecnologias de edição do genoma durante as últimas três décadas permitiram interrogar de modo sistemático a função de genes, o que pode ajudar a compreender como o genoma influencia a fisiologia celular. A engenharia genética através de recombinação homóloga (HR) tem sido o método padrão para modificar sequências genômicas. No entanto, métodos de edição do genoma por nucleases que foram desenvolvidos recentemente, como ZFN, TALEN e CRISPR/Cas, trouxeram novas perspectivas para pesquisa biomédica. Aqui, apresentamos uma breve perspectiva histórica de métodos de modificação do genoma com foco em modelos de camundongos transgênicos. Além disso, descrevemos como novas técnicas foram descobertas e aperfeiçoadas, apresentamos as mudanças de paradigma e discutimos suas limitações e aplicações para a investigação biomédica, bem como possíveis direções futuras.

Palavras-chave: Recombinação homóloga, Reparo de DNA, Cre-LoxP, ZFN, TALEN, CRISPR/Cas9.

\section{REFERENCES}

ADAMS D ET AL. 2013. Bloomsbury report on mouse embryo phenotyping: recommendations from the IMPC workshop on embryonic lethal screening. Dis Model Mech 6(3): 571579.

ADAMS MD ET AL. 2000. The genome sequence of Drosophila melanogaster. Science 287(5461): 2185-2195.

AHn S And JoYner AL. 2004. Dynamic changes in the response of cells to positive hedgehog signaling during mouse limb patterning. Cell 118(4): 505-516.

ANGUELA XM ET AL. 2013. Robust ZFN-mediated genome editing in adult hemophilic mice. Blood 122(19): 3283 3287.

Barrangou R, Fremaux C, Deveau H, Richards M, Boyaval P, MoIneau S, Romero DA and Horvath P. 2007. CRISPR provides acquired resistance against viruses in prokaryotes. Science 315(5819): 1709-1712.

Beadle GW And Tatum EL. 1941. Genetic Control of Biochemical Reactions in Neurospora. Proc Natl Acad Sci USA 27(11): 499-506.

BEDELL VM ET AL. 2012. In vivo genome editing using a highefficiency TALEN system. Nature 491(7422): 114-118.

BeErli RR, Dreier B AND BARBAs CF. 2000. Positive and negative regulation of endogenous genes by designed transcription factors. Proc Natl Acad Sci USA 97(4): $1495-$ 1500.

BHAKTA MS ET AL. 2012. Highly active zinc-finger nucleases by extended modular assembly. Genome Res 23(3): 530538.

Bibikova M, Carroll D, Segal DJ, Trautman JK, Smith J, KiM YG AND CHANDRASEGARAN S. 2001. Stimulation of homologous recombination through targeted cleavage by chimeric nucleases. Mol Cell Biol 21(1): 289-297.

BibiKova M, Golic M, Golic KG ANd CARroll D. 2002. Targeted chromosomal cleavage and mutagenesis in Drosophila using zinc-finger nucleases. Genetics 161(3): 1169-1175.

Bitinaite J, Wah DA, AgGarwal AK AND SchildKraut I. 1998. FokI dimerization is required for DNA cleavage. Proc Natl Acad Sci USA 95(18): 10570-10575.

Boch J, SchOlze H, Schornack S, LANDGRAF A, HaHn S, Kay S, LAHAYE T, NicKstadt A AND Bonas U. 2009. Breaking the code of DNA binding specificity of TAL-type III effectors. Science 326(5959): 1509-1512.

Bolotin A, Quinquis B, SOROKIN A AND EHRLICH SD. 2005. Clustered regularly interspaced short palindrome repeats (CRISPRs) have spacers of extrachromosomal origin. Microbiology 151(8): 2551-2561.

Bowman AN, VAN AMERONGEN R, PALMER TD AND Nusse R. 2013. Lineage tracing with Axin2 reveals distinct developmental and adult populations of Wnt/beta-catenin- 
responsive neural stem cells. Proc Natl Acad Sci USA 110(18): 7324-7329.

BRADLEY A ET AL. 2012. The mammalian gene function resource: the International Knockout Mouse Consortium. Mamm Genome 23(9-10): 580-586.

BRANDA CS AND DYMECKI SM. 2004. Talking about a revolution: The impact of site-specific recombinases on genetic analyses in mice. Dev Cell 6(1): 7-28.

Brinster RL, Chen Hy, Messing A, VAn Dyke T, Levine AJ AND PALMITER RD. 1984. Transgenic mice harboring SV40 T-antigen genes develop characteristic brain tumors. Cell 37(2): 367-379.

Brinster RL, Chen Hy, Trumbauer M, Senear AW, WARREN R AND PALMITER RD. 1981. Somatic expression of herpes thymidine kinase in mice following injection of a fusion gene into eggs. Cell 27(1 Pt 2): 223-231.

Brinster RL, Chen HY, WARren R, SARThy A AND PALMITER RD. 1982. Regulation of metallothionein-thymidine kinase fusion plasmids injected into mouse eggs. Nature 296(5852): 39-42.

BROWN AJ ET AL. 2013. Whole-rat conditional gene knockout via genome editing. Nat Methods 10(7): 638-640.

BuchHolz F, Ringrose L, AngRand PO, Rossi F AND STEWART AF. 1996. Different thermostabilities of FLP and cre recombinases: implications for applied site-specific recombination. Nucleic Acids Res 24(21): 4256-4262.

CAPECCHI MR. 1989. Altering the genome by homologous recombination. Science 244(4910): 1288-1292.

CAPECCHI MR. 2005. Gene targeting in mice: functional analysis of the mammalian genome for the twenty-first century. Nat Rev Genet 6(6): 507-512.

CARbery ID, Ji D, Harrington A, Brown V, Weinstein EJ, LIAW L AND CUI X. 2010. Targeted genome modification in mice using zinc-finger nucleases. Genetics 186(2): 451459.

Christian M, Cermak T, Doyle EL, Schmidt C, Zhang F, Hummel A, Bogdanove AJ ANd Voytas DF. 2010. Targeting DNA double-strand breaks with TAL effector nucleases. Genetics 186(2): 757-761.

Clarke AR, MaAndag ER, VAn RoOn M, VAn Der Lugt NM, VAN DER VALK M, HoOper ML, Berns A AND TE RIELE H. 1992. Requirement for a functional Rb-1 gene in murine development. Nature 359(6393): 328-330.

Cong L, Ran FA, Cox D, Lin S, Barretto R, Habib N, HSU PD, Wu X, JiAng W, MARRAFFINI LA AND Zhang F. 2013. Multiplex genome engineering using CRISPR/Cas systems. Science 339(6121): 819-823.

CRADICK TJ, FINE EJ, ANTICO CJ AND BAO G. 2013. CRISPR/ Cas9 systems targeting beta-globin and CCR5 genes have substantial off-target activity. Nucleic Acids Res 41(20): 9584-9592.

CRICK FH. 1958. On protein synthesis. Symp Soc Exp Biol 12: $138-163$.
DAIMON T, KIUCHI T AND TAKASU Y. 2013. Recent progress in genome engineering techniques in the silkworm, bombyx mori. Dev Growth Differ 56(1): 14-25.

Deltcheva E, Chylinski K, Sharma CM, Gonzales K, Chao Y, Pirzada ZA, EcKert MR, Vogel J AND CHARPENTIER E. 2011. CRISPR RNA maturation by transencoded small RNA and host factor RNase III. Nature 471(7340): 602-607.

Deveau H, Barrangou R, Garneau Je, Labonte J, Fremaux C, Boyaval P, Romero DA, Horvath P AND MOINEAU S. 2008. Phage response to CRISPR-encoded resistance in Streptococcus thermophilus. J Bacteriol 190(4): 1390-1400.

DICKINSON DJ, WARD JD, REINER DJ AND GOLDSTEIN B. 2013. Engineering the Caenorhabditis elegans genome using Cas9-triggered homologous recombination. Nat Methods 10(10): 1028-1034.

Doetschman T, Gregg RG, Maeda N, Hooper ML, Melton DW, Thompson S And Smithies O. 1987. Targetted correction of a mutant HPRT gene in mouse embryonic stem cells. Nature 330(6148): 576-578.

Doyon Y, Vo TD, Mendel MC, Greenberg SG, WANG J, XiA DF, Miller JC, URnOV FD, GREGORY PD AND Holmes MC. 2010. Enhancing zinc-finger-nuclease activity with improved obligate heterodimeric architectures. Nat Methods 8(1): 74-79.

ENGLER C, KANDZIA R AND MARILLONNET S. 2008. A one pot, one step, precision cloning method with high throughput capability. PLoS One 3(11): e3647.

FAVARO R ET AL. 2009. Hippocampal development and neural stem cell maintenance require Sox2-dependent regulation of Shh. Nat Neurosci 12(10): 1248-1256.

FEI JF, SCHUEZ M, TAZAKi A, TANiGUCHI Y, RoENSCH K AND TANAKA EM. 2014. CRISPR-mediated genomic deletion of Sox 2 in the axolotl shows a requirement in spinal cord neural stem cell amplification during tail regeneration. Stem Cell Reports 3(3): 444-459.

Flowers GP, Timberlake AT, MClean KC, Monaghan JR AND CREWS CM. 2014. Highly efficient targeted mutagenesis in axolotl using Cas9 RNA-guided nuclease. Development 141(10): 2165-2171.

Folger K, THOMAS K AND CAPECCHI MR. 1984. Analysis of homologous recombination in cultured mammalian cells. Cold Spring Harb Symp Quant Biol 49: 123-138.

Folger KR, WONG EA, WAHL G AND CAPECCHI MR. 1982. Patterns of integration of DNA microinjected into cultured mammalian cells: evidence for homologous recombination between injected plasmid DNA molecules. Mol Cell Biol 2(11): 1372-1387.

FORNI PE ET AL. 2006. High levels of Cre expression in neuronal progenitors cause defects in brain development leading to microencephaly and hydrocephaly. J Neurosci 26(37): 9593-9602. 
Frock RL, HU J, MeYers RM, Ho YJ, KiI E AND Alt FW. 2015. Genome-wide detection of DNA double-stranded breaks induced by engineered nucleases. Nat Biotechnol 33(2): 179-186.

Fu Y, SANDER JD, REYON D, CAScio VM AND JOUnG JK. 2014. Improving CRISPR-Cas nuclease specificity using truncated guide RNAs. Nat Biotechnol 32(3): 279-284.

FUJIHARA Y AND IKAWA M. 2014. CRISPR/Cas9-Based Genome Editing in Mice by Single Plasmid Injection. Methods Enzymol 546: 319-336.

Furth PA, St Onge L, Boger H, Gruss P, Gossen M, Kistner A, Bujard H and Hennighausen L. 1994. Temporal control of gene expression in transgenic mice by a tetracycline-responsive promoter. Proc Natl Acad Sci USA 91(20): 9302-9306.

GABRIEL R ET AL. 2011. An unbiased genome-wide analysis of zinc-finger nuclease specificity. Nat Biotechnol 29(9): 816-823.

Gaj T, Guo J, Kato Y, Sirk SJ AND Barbas CF. 2012. Targeted gene knockout by direct delivery of zinc-finger nuclease proteins. Nat Methods 9(8): 805-807.

Garneau Je, Dupuis ME, Villion M, Romero DA, Barrangou R, Boyaval P, Fremaux C, Horvath P, Magadan AH And MoIneau S. 2010. The CRISPR/ Cas bacterial immune system cleaves bacteriophage and plasmid DNA. Nature 468(7320): 67-71.

GATES CA AND COX MM. 1988. FLP recombinase is an enzyme. Proc Natl Acad Sci USA 85(13): 4628-4632.

Golic KG AND LindQUist S. 1989. The FLP recombinase of yeast catalyzes site-specific recombination in the Drosophila genome. Cell 59(3): 499-509.

Gordon JW, Scangos GA, Plotkin DJ, Barbosa JA AND RUDDLE FH. 1980. Genetic transformation of mouse embryos by microinjection of purified DNA. Proc Natl Acad Sci USA 77(12): 7380-7384.

Gratz SJ, Cummings AM, NGUYen JN, Hamm DC, Donohue LK, HARrison MM, Wildonger J AND O'CONNORGILES KM. 2013. Genome engineering of Drosophila with the CRISPR RNA-guided Cas9 nuclease. Genetics 194(4): 1029-1035.

GREISMAN HA AND PABO CO. 1997. A general strategy for selecting high-affinity zinc finger proteins for diverse DNA target sites. Science 275(5300): 657-661.

GRINDLEY ND, Whiteson KL AND Rice PA. 2006. Mechanisms of site-specific recombination. Annu Rev Biochem 75: 567-605.

Guo X, Zhang T, Hu Z, Zhang Y, Shi Z, WAnG Q, Cui Y, WANG F, ZHAO H AND CHEN Y. 2014. Efficient RNA/ Cas9-mediated genome editing in Xenopus tropicalis. Development 141(3): 707-714.

Hammer Re, Pursel VG, ReXroad Jr CE, Wall RJ, BOLt DJ, EBERT KM, PALMITER RD AND BRINSTER RL.
1985. Production of transgenic rabbits, sheep and pigs by microinjection. Nature 315(6021): 680-683.

Harada N, TAmai Y, IshiKawa T, SAUER B, TAKaKU K, OSHIMA M AND TAKETO MM. 1999. Intestinal polyposis in mice with a dominant stable mutation of the beta-catenin gene. EMBO J 18(21): 5931-5942.

HARRISON MM, JENKINS BV, O'CONNOR-GILES KM AND WILDONGER J. 2014. A CRISPR view of development. Genes Dev 28(17): 1859-1872.

HAYASHI S, TENZEN T AND MCMAHON AP. 2003. Maternal inheritance of Cre activity in a Sox 2 Cre deleter strain. Genesis 37(2): 51-53.

He LZ, Tribioli C, Rivi R, Peruzzi D, Pelicci PG, Soares V, Cattoretti G AND Pandolfi PP. 1997. Acute leukemia with promyelocytic features in PML/ RARalpha transgenic mice. Proc Natl Acad Sci USA 94(10): 5302-5307.

Holt N, Wang J, Kim K, Friedman G, Wang X, Taupin V, Crooks GM, Kohn DB, Gregory PD, Holmes MC AND CANNON PM. 2010. Human hematopoietic stem/ progenitor cells modified by zinc-finger nucleases targeted to CCR5 control HIV-1 in vivo. Nat Biotechnol 28(8): 839-847.

HSU PD ET AL. 2013. DNA targeting specificity of RNAguided Cas9 nucleases. Nat Biotechnol 31(9): 827-832.

HWANG WY, Fu Y, REYON D, MAEDER ML, TSAI SQ, SANDER JD, PETERSON RT, YEH JR AND JOUNG JK. 2013. Efficient genome editing in zebrafish using a CRISPR-Cas system. Nat Biotechnol 31(3): 227-229.

Ishino Y, Shinagawa H, Makino K, Amemura M And NAKATA A. 1987. Nucleotide sequence of the iap gene, responsible for alkaline phosphatase isozyme conversion in Escherichia Coli, and identification of the gene product. J Bacteriol 169(12): 5429-5433.

JAO LE, WENTE SR AND CHEN W. 2013. Efficient multiplex biallelic zebrafish genome editing using a CRISPR nuclease system. Proc Natl Acad Sci USA 110(34): $13904-$ 13909.

JENSEN P AND DYMECKI SM. 2014. Essentials of recombinasebased genetic fate mapping in mice. Methods Mol Biol 1092: 437-454.

JiAnG W, Zhou H, BI H, Fromm M, YANG B AND WeEKS DP. 2013. Demonstration of CRISPR/Cas9/sgRNA-mediated targeted gene modification in arabidopsis, tobacco, sorghum and rice. Nucleic Acids Res 41(20): e188.

JiNEK M, CHYLINSKI K, FONFARA I, HAUER M, DOUDNA JA AND CHARPENTIER E. 2012. A programmable dual-RNAguided DNA endonuclease in adaptive bacterial immunity. Science 337(6096): 816-821.

JOYNER AL, SKARnes WC AND RossAnT J. 1989. Production of a mutation in mouse En-2 gene by homologous recombination in embryonic stem cells. Nature 338(6211): 153-156. 
KaWase E, Suemori H, Takahashi N, OKazaki K, HASHIMOTO K AND NAKATSUJI N. 1994. Strain difference in establishment of mouse embryonic stem (ES) cell lines. Int J Dev Biol 38(2): 385-390.

KIM H AND KIM JS. 2014. A guide to genome engineering with programmable nucleases. Nat Rev Genet 15(5): 321-334.

KIM Y ET AL. 2013a. A library of TAL effector nucleases spanning the human genome. Nat Biotechnol 31(3): 251258.

Kim YG, Cha J And Chandrasegaran S. 1996. Hybrid restriction enzymes: zinc finger fusions to Fok I cleavage domain. Proc Natl Acad Sci USA 93(3): 1156-1160.

KIM YG AND CHANDRASEGARAN S. 1994. Chimeric restriction endonuclease. Proc Natl Acad Sci USA 91(3): 883-887.

Kim YK, WeE G, PARK J, Kim J, BAEK D, Kim JS AND Kim VN. 2013b. TALEN-based knockout library for human micro RNAs. Nat Struct Mol Biol 20(12): 1458-1464.

KING MC AND WILSON AC. 1975. Evolution at two levels in humans and chimpanzees. Science 188(4184): 107-116.

KISKINIS E ET AL. 2014. "Pathways disrupted in human ALS motor neurons identified through genetic correction of mutant SOD1. Cell Stem Cell 14(6): 781-795.

Koller BH, Hagemann LJ, DOETSCHMAN T, HAGAMAN JR, HuAnG S, Williams PJ, First NL, MAEDAN AND SMithiES O. 1989. Germ-line transmission of a planned alteration made in a hypoxanthine phosphoribosyltransferase gene by homologous recombination in embryonic stem cells. Proc Natl Acad Sci USA 86(22): 8927-8931.

Koller BH, Marrack P, KAPpler JW AND SMithies O. 1990. Normal development of mice deficient in beta $2 \mathrm{M}, \mathrm{MHC}$ class I proteins, and CD8+ T cells. Science 248(4960): 1227-1230.

Konermann S, Brigham MD, Trevino AE, Hsu PD, Heidenreich M, Cong L, Platt RJ, Scott DA, Church GM AND ZHANG F. 2013. Optical control of mammalian endogenous transcription and epigenetic states. Nature 500(7463): 472-476.

Koscielny G ET AL. 2014. The International Mouse Phenotyping Consortium Web Portal, a unified point of access for knockout mice and related phenotyping data. Nucleic Acids Res 42(Database issue): D802-809.

KRENTZ NA, NIAN C AND LYNN FC. 2014. TALEN/CRISPRMediated eGFP Knock-In Add-On at the OCT4 Locus Does Not Impact Differentiation of Human Embryonic Stem Cells towards Endoderm. PLoS One 9(12): e114275.

LAGACE DC ET AL. 2007. Dynamic contribution of nestinexpressing stem cells to adult neurogenesis. J Neurosci 27(46): 12623-12629.

Lakso M, Sauer B, Mosinger Jr B, Lee EJ, Manning RW, YU SH, Mulder KL AND Westphal H. 1992. Targeted oncogene activation by site-specific recombination in transgenic mice. Proc Natl Acad Sci USA 89(14): 6232 6236.

LANIO T, JELTSCH A AND PINGOUd A. 2000. On the possibilities and limitations of rational protein design to expand the specificity of restriction enzymes: a case study employing EcoRV as the target. Protein Eng 13(4): 275-281.

LAO Z, RAJU GP, BAI CB AND JOYNER AL. 2012. MASTR: a technique for mosaic mutant analysis with spatial and temporal control of recombination using conditional floxed alleles in mice. Cell Rep 2(2): 386-396.

LEE AY AND LLOYD KC. 2014. Conditional targeting of Ispd using paired Cas9 nickase and a single DNA template in mice. FEBS Open Bio 4: 637-642.

LEVINE M AND TJIAN R. 2003. Transcription regulation and animal diversity. Nature 424(6945): 147-151.

LEWANDOSKI M. 2001. Conditional control of gene expression in the mouse. Nat Rev Genet 2(10): 743-755.

LEWANDOSKI M AND MARTIN GR. 1997. Cre-mediated chromosome loss in mice. Nat Genet 17(2): 223-225.

Li C, Qi R, Singleterry R, Hyle J, Balch A, Li X, Sublett J, Berns H, VALEntine M, VALEnTine V AND SHERR CJ. 2014. Simultaneous gene editing by injection of mRNAs encoding transcription activator-like effector nucleases into mouse zygotes. Mol Cell Biol 34(9): 16491658.

LI H ET AL. 2011. In vivo genome editing restores haemostasis in a mouse model of haemophilia. Nature 475(7355): 217 221.

Li HL ET AL. 2014. Precise Correction of the Dystrophin Gene in Duchenne Muscular Dystrophy Patient Induced Pluripotent Stem Cells by TALEN and CRISPR-Cas9. Stem Cell Reports.

LiU P, Long L, Xiong K, YU B, Chang N, Xiong JW, ZhU Z AND LIU D. 2014. Heritable/conditional genome editing in C. elegans using a CRISPR-Cas9 feeding system. Cell Res 24(7): 886-889.

Lobe CG, KoOp KE, KREPPNER W, LOMELI H, GERTSENSTEIN M AND NAGY A. 1999. Z/AP, a double reporter for cremediated recombination. Dev Biol 208(2): 281-292.

Long C, McAnally JR, Shelton JM, Mireault AA, BAsSel-Duby R AND Olson EN. 2014. Prevention of muscular dystrophy in mice by CRISPR/Cas9mediated editing of germline DNA. Science 345(6201): 1184-1188.

Loonstra A, Vooijs M, Beverloo HB, Allak BA, VAN Drunen E, KANAAR R, BERnS A AND JONKERS J. 2001. Growth inhibition and DNA damage induced by Cre recombinase in mammalian cells. Proc Natl Acad Sci USA 98(16): 9209-9214.

LOVELL-BADGE R AND RoBERTSON E. 1990. XY female mice resulting from a heritable mutation in the primary testisdetermining gene, TDY. Development 109(3): 635-646. 
Low Be, Krebs MP, Joung JK, Tsai SQ, Nishina PM AND WILES MV. 2013. Correction of the Crb1rd8 allele and retinal phenotype in C57BL/6N mice via TALENmediated homology-directed repair. Invest Ophthalmol Vis Sci 55(1): 387-395.

Ma M, Zhao K, WU W, Sun R and Fei J. 2014. Dynamic expression of $\mathrm{N}$-myc in mouse embryonic development using an enhanced green fluorescent protein reporter gene in the N-myc locus. Dev Growth Differ 56(2): 152160.

Ma S, Chang J, Wang X, LiU Y, Zhang J, Lu W, Gao J, Shi R, ZHAO P AND XIA Q. 2014. CRISPR/Cas9 mediated multiplex genome editing and heritable mutagenesis of BmKu70 in Bombyx mori. Sci Rep 4: 4489.

Ma Y, Shen B, Zhang X, Lu Y, Chen W, Ma J, Huang $\mathrm{X}$ AND Zhang L. 2014. Heritable multiplex genetic engineering in rats using CRISPR/Cas9. PLoS One 9(3): e89413.

Ma Y, Zhang X, Shen B, Lu Y, Chen W, Ma J, Bai L, HuANG X AND ZHANG L. 2013. Generating rats with conditional alleles using CRISPR/Cas9. Cell Res 24(1): 122-125.

Macpherson D, Sage J, Kim T, Ho D, Mclaughlin ME AND JACKS T. 2004. Cell type-specific effects of Rb deletion in the murine retina. Genes Dev 18(14): 16811694.

MAeder ML ET AL. 2013. Targeted DNA demethylation and activation of endogenous genes using programmable TALE-TET1 fusion proteins. Nat Biotechnol 31(12): 11371142.

MAEDER ML ET AL. 2008. Rapid “open-source” engineering of customized zinc-finger nucleases for highly efficient gene modification. Mol Cell 31(2): 294-301.

Mahon KA, Chepelinsky AB, Khillan JS, Overbeek PA, Piatigorsky J AND WestPhal H. 1987. Oncogenesis of the lens in transgenic mice. Science 235(4796): 16221628.

Mali P, YANG L, Esvelt KM, AACh J, Guell M, DicArlo JE, Norville JE AND ChurCh GM. 2013. RNA-guided human genome engineering via Cas9. Science 339(6121): 823-826.

Mansour SL, Thomas KR AND CAPECCHI MR. 1988. Disruption of the proto-oncogene int-2 in mouse embryoderived stem cells: a general strategy for targeting mutations to non-selectable genes. Nature 336(6197): 348352.

MARTIN GR. 1981. Isolation of a pluripotent cell line from early mouse embryos cultured in medium conditioned by teratocarcinoma stem cells. Proc Natl Acad Sci USA 78(12): 7634-7638.

Mazeyrat S, Saut N, Grigoriev V, MahadeVaiah SK, OJARIKRE OA, RATTIGAN A, Bishop C, EICHER EM, Mitchell MJ AND Burgoyne PS. 2001. A Y-encoded subunit of the translation initiation factor Eif2 is essential for mouse spermatogenesis. Nat Genet 29(1): 49-53.

MCGINNIS W AND KRUMLAUF R. 1992. Homeobox genes and axial patterning. Cell 68(2): 283-302.

MCLEOD M, CRAFT S AND BROACH JR. 1986. Identification of the crossover site during FLP-mediated recombination in the Saccharomyces cerevisiae plasmid 2 microns circle. Mol Cell Biol 6(10): 3357-3367.

MECKLER JF ET AL. 2013. Quantitative analysis of TALEDNA interactions suggests polarity effects. Nucleic Acids Res 41(7): 4118-4128.

Mendenhall EM, WiLliamson KE, REyon D, Zou JY, RAM O, JOUNG JK AND BERNSTEIN BE. 2013. Locus-specific editing of histone modifications at endogenous enhancers. Nat Biotechnol 31(12): 1133-1136.

Meyer M, De Angelis MH, Wurst W and Kuhn R. 2010. Gene targeting by homologous recombination in mouse zygotes mediated by zinc-finger nucleases. Proc Natl Acad Sci USA 107(34): 15022-15026.

MiLlER JC ET AL. 2007. An improved zinc-finger nuclease architecture for highly specific genome editing. Nat Biotechnol 25(7): 778-785.

Miller JC ET AL. 2010. A TALE nuclease architecture for efficient genome editing. Nat Biotechnol 29(2): 143-148.

MiYANARI Y, ZIEGLER-BIRLING C AND TORRES-PADILla ME. 2013. Live visualization of chromatin dynamics with fluorescent TALEs. Nat Struct Mol Biol 20(11): 1321 1324.

Moehle EA, Rock JM, LeE YL, Jouvenot Y, DeKelver RC, GRegory PD, URnOV FD AND Holmes MC. 2007. Targeted gene addition into a specified location in the human genome using designed zinc finger nucleases. Proc Natl Acad Sci USA 104(9): 3055-3060.

Mojica FJ, Diez-Villasenor C, Soria E And Juez G. 2000. Biological significance of a family of regularly spaced repeats in the genomes of archaea, bacteria and mitochondria. Mol Microbiol 36(1): 244-246.

Mojica FJ, Diez-Villasenor C, Garcia-Martinez J AND SORIA E. 2005. Intervening sequences of regularly spaced prokaryotic repeats derive from foreign genetic elements. J Mol Evol 60(2): 174-182.

Moscou MJ And Bogdanove AJ. 2009. A simple cipher governs DNA recognition by TAL effectors. Science 326(5959): 1501.

NIU Y ET AL. 2014. Generation of gene-modified cynomolgus monkey via Cas9/RNA-mediated gene targeting in onecell embryos. Cell 156(4): 836-843.

OKabe M, IKaWA M, Kominami K, NAKANishi T AND NiSHIMUNE Y. 1997. 'Green mice' as a source of ubiquitous green cells. FEBS Lett 407(3): 313-319.

ORBAN PC, ChUI D AND MARTH JD. 1992. Tissue- and sitespecific DNA recombination in transgenic mice. Proc Natl Acad Sci USA 89(15): 6861-6865. 
OSBORN MJ ET AL. 2013. TALEN-based gene correction for epidermolysis bullosa. Mol Ther 21(6): 1151-1159.

PALMiter RD, Brinster RL, HAMmer RE, Trumbauer Me, Rosenfeld MG, Birnberg NC AND Evans RM. 1982. Dramatic growth of mice that develop from eggs microinjected with metallothionein-growth hormone fusion genes. Nature 300(5893): 611-615.

PATTANAYAK V, Lin S, GuiLinger JP, MA E, DOUdNA JA AND LIU DR. 2013. High-throughput profiling of off-target DNA cleavage reveals RNA-programmed Cas9 nuclease specificity. Nat Biotechnol 31(9): 839-843.

PEREZ EE ET AL. 2008. Establishment of HIV-1 resistance in CD4+ $\mathrm{T}$ cells by genome editing using zinc-finger nucleases. Nat Biotechnol 26(7): 808-816.

PlatT RJ ET AL. 2014. CRISPR-Cas9 knockin mice for genome editing and cancer modeling. Cell 159(2): 440-455.

Pourcel C, SAlvignol G AND Vergnaud G. 2005. CRispr elements in Yersinia pestis acquire new repeats by preferential uptake of bacteriophage DNA, and provide additional tools for evolutionary studies. Microbiology 151(Pt 3): 653-663.

QIU Z ET AL. 2013. High-efficiency and heritable gene targeting in mouse by transcription activator-like effector nucleases. Nucleic Acids Res 41(11): e120.

RAMIREZ CL ET AL. 2008. Unexpected failure rates for modular assembly of engineered zinc fingers. Nat Methods 5(5): 374-375.

Ren SY, PAsqualetti M, Dierich A, Le Meur M AND RiJli FM. 2002. A Hoxa2 mutant conditional allele generated by Flp- and Cre-mediated recombination. Genesis 32(2): 105-108.

REN X ET AL. 2013. Optimized gene editing technology for Drosophila melanogaster using germ line-specific Cas9. Proc Natl Acad Sci USA 110(47): 19012-19017.

Romer P, Hahn S, Jordan T, Strauss T, Bonas U AND LAHAYE T. 2007. Plant pathogen recognition mediated by promoter activation of the pepper Bs 3 resistance gene. Science 318(5850): 645-648.

SANDER JD ET AL. 2010. Selection-free zinc-finger-nuclease engineering by context-dependent assembly (CoDA). Nat Methods 8(1): 67-69.

SANDER JD AND JOUNG JK. 2014. CRISPR-Cas systems for editing, regulating and targeting genomes. Nat Biotechnol 32(4): 347-355.

SAUER B AND HENDERSON N. 1988. Site-specific DNA recombination in mammalian cells by the Cre recombinase of bacteriophage P1. Proc Natl Acad Sci USA 85(14): 5166-5170.

Scacheri PC, Crabtree JS, Novotny eA, GarrettBeal L, Chen A, Edgemon KA, Marx SJ, Spiegel AM, Chandrasekharappa SC AND Collins FS. 2001. Bidirectional transcriptional activity of PGK-neomycin and unexpected embryonic lethality in heterozygote chimeric knockout mice. Genesis 30(4): 259-263.

SCHMIDT-SUPPRIAN M, WUNDERLICH FT AND RAJEWSKY K. 2007. Excision of the Frt-flanked neo (R) cassette from the CD19cre knock-in transgene reduces Cre-mediated recombination. Transgenic Res 16(5): 657-660.

SCHMidT Ee, TAYlor DS, PRIGge JR, BARnetT S AND CAPECCHI MR. 2000. Illegitimate Cre-dependent chromosome rearrangements in transgenic mouse spermatids. Proc Natl Acad Sci USA 97(25): 1370213707.

Schulte-Merker S AND Stainier DY. 2014. Out with the old, in with the new: reassessing morpholino knockdowns in light of genome editing technology. Development 141(16): 3103-3104.

SCHWANK G ET AL. 2013. Functional repair of CFTR by CRISPR/Cas9 in intestinal stem cell organoids of cystic fibrosis patients. Cell Stem Cell 13(6): 653-658.

SCHWARTZBERG PL, GOFF SP AND ROBERTSON EJ. 1989. Germ-line transmission of a c-abl mutation produced by targeted gene disruption in ES cells. Science 246(4931): 799-803.

Schwenk F, Sauer B, Kukoc N, Hoess R, Muller W, Kocks C, KUHN R AND RAJEWSKY K. 1997. Generation of Cre recombinase-specific monoclonal antibodies, able to characterize the pattern of Cre expression in cretransgenic mouse strains. J Immunol Methods 207(2): 203-212.

SEBASTIANO V ET AL. 2011. In situ genetic correction of the sickle cell anemia mutation in human induced pluripotent stem cells using engineered zinc finger nucleases. Stem Cells 29(11): 1717-1726.

SMithies O, GREGG RG, BogGS SS, KorALEWSKI MA AND KUCHERLAPATI RS. 1985. Insertion of DNA sequences into the human chromosomal beta-globin locus by homologous recombination. Nature 317(6034): 230-234.

SOMMER D ET AL. 2014. Efficient genome engineering by targeted homologous recombination in mouse embryos using transcription activator-like effector nucleases. Nat Commun 5: 3045.

SPRADLING AC AND RUBIN GM. 1982. Transposition of cloned $\mathrm{P}$ elements into Drosophila germ line chromosomes. Science 218(4570): 341-347.

SternberG N AND Hamilton D. 1981. Bacteriophage P1 site-specific recombination. I. Recombination between loxP sites. J Mol Biol 150(4): 467-486.

Stolfi A, Gandhi S, Salek F And Christiaen L. 2014. Tissue-specific genome editing in Ciona embryos by CRISPR/Cas9. Development 141(21): 4115-4120.

Straub C, Granger AJ, SAulnier JL and SABatini BL. 2014. CRISPR/Cas9-mediated gene knock-down in postmitotic neurons. PLoS One 9(8): e105584. 
Sun Y, CHEN X AND XIAO D. 2007. Tetracycline-inducible expression systems: new strategies and practices in the transgenic mouse modeling. Acta Biochim Biophys Sin (Shanghai) 39(4): 235-246.

Sung YH, BAeK IJ, Kim DH, JeOn J, LeE J, LeE K, JeOnG D, KIM JS AND LEE HW. 2013. Knockout mice created by TALEN-mediated gene targeting. Nat Biotechnol 31(1): 23-24.

SzczepeK M, Brondani V, Buchel J, SERrano L, SEgal DJ AND CATHOMEN T. 2007. Structure-based redesign of the dimerization interface reduces the toxicity of zinc-finger nucleases. Nat Biotechnol 25(7): 786-793.

Tamamaki N, Yanagawa Y, TOMioka R, Miyazaki J, OBATA K AND KANEKO T. 2003. Green fluorescent protein expression and colocalization with calretinin, parvalbumin, and somatostatin in the GAD67-GFP knock-in mouse. J Comp Neurol 467(1): 60-79.

TANG JC, SZIKRA T, KoZOROVITSKIY Y, TEIXIERA M, SABATINI BL, ROSKA B AND CEPKO CL. 2013. A nanobody-based system using fluorescent proteins as scaffolds for cellspecific gene manipulation. Cell 154(4): 928-939.

THOMAS KR AND CAPECCHI MR. 1987. Site-directed mutagenesis by gene targeting in mouse embryo-derived stem cells. Cell 51(3): 503-512.

THOMAS KR AND CAPECCHI MR. 1990. Targeted disruption of the murine int-1 proto-oncogene resulting in severe abnormalities in midbrain and cerebellar development. Nature 346(6287): 847-850.

Treen N, Yoshida K, Sakuma T, Sasaki H, Kawai N, YAmamoto T AND SASAKURA Y. 2013. Tissue-specific and ubiquitous gene knockouts by TALEN electroporation provide new approaches to investigating gene function in Ciona. Development 141(2): 481-487.

Tronche F, Casanova E, Turiault M, Sahly I And KeLlendonK C. 2002. When reverse genetics meets physiology: the use of site-specific recombinases in mice. FEBS Lett 529(1): 116-121.

Turan S AND Bode J. 2011. Site-specific recombinases: from tag-and-target- to tag-and-exchange-based genomic modifications. FASEB J 25(12): 4088-4107.

Urnov FD, Miller JC, LeE YL, BeAusejour CM, Rock JM, Augustus S, JAMIESON AC, PORTEUs MH, GREGORY PD AND HOLMES MC. 2005. Highly efficient endogenous human gene correction using designed zinc-finger nucleases. Nature 435(7042): 646-651.

Urnov FD, Rebar EJ, Holmes MC, Zhang HS AND GREGORY PD. 2010. Genome editing with engineered zinc finger nucleases. Nat Rev Genet 11(9): 636-646.

VAn Amerongen R, Bowman AN And Nusse R. 2012. Developmental stage and time dictate the fate of Wnt/betacatenin-responsive stem cells in the mammary gland. Cell Stem Cell 11(3): 387-400.
VENTER JC ET AL. 2001. The sequence of the human genome. Science 291(5507): 1304-1351.

VoOIJS M, JONKERS J AND BERNS A. 2001. A highly efficient ligand-regulated Cre recombinase mouse line shows that LoxP recombination is position dependent. EMBO Rep 2(4): 292-297.

WANG H ET AL. 2013. TALEN-mediated editing of the mouse Y chromosome. Nat Biotechnol 31(6): 530-532.

WANG S, Sengel C, EMERSon MM AND CEPKo CL. 2014. A gene regulatory network controls the binary fate decision of rod and bipolar cells in the vertebrate retina. Dev Cell 30(5): 513-527.

WANG X, WANG Y, WU X, WANG J, WANG Y, QIU Z, ChanG T, Huang H, Lin RJ and YeE JK. 2015. Unbiased detection of off-target cleavage by CRISPR-Cas9 and TALENs using integrase-defective lentiviral vectors. Nat Biotechnol 33(2): 175-178.

WATERSTON RH ET AL. 2002. Initial sequencing and comparative analysis of the mouse genome. Nature 420(6915): 520-562.

WATSON JD AND CRICK FH. 1953. Genetical implications of the structure of deoxyribonucleic acid. Nature 171(4361): 964-967.

WhiteHEAD AS AND SACKSTEIN R. 1985. Molecular biology of the human and mouse MHC class III genes: phylogenetic conservation, genetics and regulation of expression. Immunol Rev 87: 185-208.

Wolfe SA, NeKludova L and Pabo CO. 2000. DNA recognition by Cys2His2 zinc finger proteins. Annu Rev Biophys Biomol Struct 29: 183-212.

WU L ET AL. 2003. Extra-embryonic function of Rb is essential for embryonic development and viability. Nature 421(6926): 942-947.

WU Y ET AL. 2014. Correction of a genetic disease by CRISPRCas9-mediated gene editing in mouse spermatogonial stem cells. Cell Res.

Xing HL, Dong L, Wang ZP, Zhang HY, Han CY, LiU B, WANG XC and Chen QJ. 2014. A CRISPR/Cas9 toolkit for multiplex genome editing in plants. BMC Plant Biol 14(1): 327.

Xu GL AND Bestor TH. 1997. Cytosine methylation targetted to pre-determined sequences. Nat Genet 17(4): 376-378.

Xue Z, WU M, Wen K, REN M, LONG L, ZHANG X and Gao G. 2014. CRISPR/Cas9 Mediates Efficient Conditional Mutagenesis in Drosophila. G3 (Bethesda) 4(11): $2167-$ 2173.

YAMAMOTO M, SHOOK NA, KanisicaK O, YAMAMOTO S, WOSCZYNA MN, CAMP JR AND GOLDHAMER DJ. 2009. A multifunctional reporter mouse line for Cre- and FLPdependent lineage analysis. Genesis 47(2): 107-114.

Yang H, Wang H, Shivalila CS, Cheng AW, Shi L AND JAENISCH R. 2013. One-step generation of mice carrying 
reporter and conditional alleles by CRISPR/Cas-mediated genome engineering. Cell 154(6): 1370-1379.

YAng M, ReYnoso J, JiAng P, Li L, Moossa AR AND Hoffman RM. 2004. Transgenic nude mouse with ubiquitous green fluorescent protein expression as a host for human tumors. Cancer Res 64(23): 8651-8656.

Yin H, Xue W, Chen S, Bogorad RL, Benedetti e, Grompe M, KOTELIANSKY V, SHARP PA, JACKS T AND ANDERSON DG. 2014. Genome editing with Cas9 in adult mice corrects a disease mutation and phenotype. Nat Biotechnol 32(6): 551-553.
YUSA K ET AL. 2011. Targeted gene correction of alpha1antitrypsin deficiency in induced pluripotent stem cells. Nature 478(7369): 391-394.

ZhaNG S, Li L, KENDRICK SL, GerARD RD AND ZHU H. 2014. TALEN-mediated somatic mutagenesis in murine models of cancer. Cancer Res 74(18): 5311-5321.

ZiJlstra M, Li E, SaJjadi F, Subramani S AND JaEnisch R. 1989. Germ-line transmission of a disrupted beta 2-microglobulin gene produced by homologous recombination in embryonic stem cells. Nature 342(6248): 435-438. 